\title{
Formas y funciones de la poesía religiosa de Antonio Geraldini escrita en la época fernandina*
}

Forms and functions of Antonio Geraldini's
religious poetry in the age of Ferdinand II

Martin FRÜH

Landesarchiv Nordrhein-Westfalen, Abteilung Rheinland, Duisburg (Alemania)

martinfrueh@gmx.de

\begin{abstract}
The present article deals with the religious works of the Neo-Latin poet Antonio Geraldini (†1488). During his time as a royal official at the Court of Aragón, Geraldini wrote three major pieces of religious poetry. The structure and content of these works are analyzed in regard to the literary tradition and present. Geraldini's religious legacy proves to be sophisticated literature, stimulated by his didactic intentions. Situated in a Hispanic historical and cultural context and printed in Rome, these poems also play a part in the orchestration of propaganda conducted by the Royal Family in Catholic Europe.
\end{abstract}

Keywords: Neo-Latin pastoral; Neo-Latin epodes; fasti; goigs.
Resumen: En el presente artículo se muestra la obra religiosa del poeta neolatino Antonio Geraldini († 1488). Trabajando como funcionario real en la Corte de Aragón, el humanista de Umbría escribió tres obras poéticas de carácter espiritual. La estructura y el contenido de esas obras se analizan dentro del marco de la tradición y de la actualidad literarias. El legado espiritual de Antonio Geraldini resulta ser una literatura refinada, estimulada por su propósito docente. Situadas en un contexto histórico-cultural hispánico e impresas en Roma, dichas poesías formaron parte de la orquestación publicitaria de la familia real en la Europa católica.

Palabras clave: bucólica neolatina; epodos neolatinos; fastos; goigs.

\section{El MARCO BIOGRÁFICO: ANTONIO GERALDINI Y FERNANDO EL CATÓLICO}

El 3 de mayo de 1469 dos italianos, enviados por el rey de Nápoles, llegaron magno cum periculo et rerum... inopia a la ciudad costera de Tarragona ${ }^{1}$. Se tra-

* Agradezco a Dña. Gema Ramos Martínez (Alcalá de Henares) la revisión del texto castellano.

1 Hartmut Peter, Die Vita Angeli Geraldini des Antonio Geraldini. Biograpbie eines Kurienbischofs und Diplomaten des Quattrocento. Text und Untersuchungen (Europäische Hochschulschriften, III, 570), Fráncfort del Meno, 1993, p. 253. 
taba del embajador Angelo Geraldini (1422-1486)², gran diplomático y obispo curial, y de su nieto Antonio Geraldini (1448 o 1449-1488) ${ }^{3}$. Fue el primer gran viaje de este último. Antonio Geraldini empezó sus estudios humanísticos en su ciudad de nacimiento Amelia (Umbría) bajo la guía del grammaticus Grifone ${ }^{4}$. A la edad de 10 años, salió de Amelia y pasó (según escribe él) por Perugia, Fano y Bolonia. Entre 1465 y 1466 se encontró en el entorno de la corte de los Sforza en Milán y de 1466 hasta 1468 en el círculo de los Medici en Florencia. Sin embargo, resultaron inútiles sus intentos de establecerse de manera definitiva en alguna corte italiana 5 .

En Tarragona, el rey Juan II de Aragón cum omni concilio suo et nobilium curialium caterua dio la bienvenida a los enviados ${ }^{6}$. Por su parte, el rey no dudó en encomendarles una misión diplomática: animar a los grandes y a las municipalidades del Reino de Aragón a sustentar la guerra civil contra los insurgentes catalanes de manera militar y financiera. Es así que los Geraldini se trasladaron a Valencia, donde Angelo, el 17 de junio, logró la concesión de un donativo por parte del consejo municipal. Quedándose en Valencia, es muy probable que nuestros italianos conocieran allí a una persona que iba a desempeñar un papel esencial para el futuro profesional del joven humanista: Fernando de Aragón, hijo del rey Juan II, quien llegó a Valencia el 16 de julio de $1469^{7}$.

En todo caso, sabemos que Antonio Geraldini impresionó a la familia real al componer y declamar poesías en alabanza a Fernando. Además, recibió el apoyo

2 Sobre Angelo Geraldini, véase Jürgen PeTERsohn, Ein Diplomat des Quattrocento. Angelo Geraldini (1422-1486) (Bibliothek des Deutschen Historischen Instituts in Rom, 62), Tubinga, 1985; ÍD., Geraldini, Angelo, en Dizionario Biografico degli Italiani, t. 53, Roma, 2000, pp. 316-321; ÍD., Azioni di governo e missioni diplomatiche di Angelo Geraldini (1422-1486), en Tiziana DE ANGELIS (ed.), I Geraldini di Amelia nell'Europa del Rinascimento. Atti del Convegno Storico Internazionale, Amelia, 21-22 novembre 2003, Terni y Amelia, 2004, pp. 19-24. Sobre la familia Geraldini, véase también ÍD., Amelia, Roma e Santo Domingo. Alessandro Geraldini e la sua famiglia alla luce di un convegno recente e di fonti contemporanee, en Quellen und Forschungen aus italienischen Archiven und Bibliotheken, 76 (1996), pp. 253-273.

3 Para un breve resumen de los estudios históricos y filológicos sobre Antonio Geraldini, véase Martin FrÜH, Geraldini, Antonio, en Juan Francisco DomíngUEZ, Diccionario biográfico y bibliográfico del bumanismo español (ss. XV-XVII), Madrid, 2012, pp. 355-359.

4 Eduardo D'ANGELo, Maestro Grifone e i suoi allievi. Cultura latina e scuola in Amelia alla metà del Quattrocento (Quaderni del Centro per il collegamento degli studi medievali e umanistici in Umbria, 49), Spoleto, 2011, p. 80.

5 Martin FrÜH, Antonio Geraldini († 1488). Leben, Dichtung und soziales Beziehungsnetz eines italienischen Humanisten am aragonesischen Königshof. Mit einer Edition seiner «Carmina ad Iohannam Aragonum» (Geschichte und Kultur der Iberischen Welt, 2), Münster, 2005, pp. 12-16.

6 Hartmut Peter, Die Vita... [ver n. 1], p. 254.

7 Martin FrÜH, Antonio Geraldini... [ver n. 5], p. 18. 
de su influyente tío Angelo ${ }^{8}$. Así que el 1 de octubre de aquel año, Juan II encargó a su hijo coronar a Antonio como poeta laureado y le nombró secretario del rey9:

...cum dilectus noster insignis uir Anthonius Geraldinus ex Ameria multa ex carminibus, que in laudem uestram composuit, decantasset essemusque eius cum ingenium tum dicendi dulcedinem admirati, nostre dignacionis esse duximus eum omni bonore prosequi ac in poetarum numerum ordinemque euehere. Verum enim uero... quoniam pacis et ocii munera duceremus, statuimus, ut uos illi lauream daretis uestraque et auctoritate et, ut aiunt, manu inter poetas numeraretur. Nos satis officio nostro fecisse arbitramur, quando eum inter secretorum participes, quos uulgus secretarios uocat, adscripsimus, quemadmodum et per presentes adscribimus. Itaque, fili carissime, hortamur, ut inter eos, qui secretarii uocantur, adnumeretur, nostraque et uestra ipsius auctoritate lauream usumque auri illi concedatis.

Esta coronación tuvo lugar en Valladolid entre el 19 de octubre de 1469 y el 2 de enero de 1470, siendo aparentemente la primera coronación de un poeta laureado en la Península Ibérica ${ }^{10}$. Su nombramiento de secretario, de otra parte, le abrió a Antonio el camino al servicio real, en cuyo ejercicio iba a actuar también como diplomático, consejero y (desde 1480) cronista de la Corona de Aragón ${ }^{11}$. Se destaca particularmente su discurso de obediencia ante el papa Inocencio VIII, presentado en septiembre de 1486 (Oratio in obsequio canonice exbibito nomine Ferdinandi regis et Helisabet regine Hispanie Innocentio VIII), que muestra a Geraldini como hombre de educación ibérica: Ego licet natione sim Italus, tamen Hispanus sum educatione ${ }^{12}$.

Y efectivamente, es en el Reino de Aragón ${ }^{13}$ donde nuestro humanista encontró condiciones tan favorables de vida y para componer poesías que se negó a volver a Italia. Trabajando en la cancillería real, «el primer centre de l'humanisme llatí a Catalunya» ${ }^{14}$, Antonio Geraldini no sólo gozó de buena reputación en la corte, sino que se integró rápidamente en el entorno sociocultural de sus colegas.

8 Ibid., p. 19 con n. 129.

9 Barcelona, Archivo de la Corona de Aragón, Cancillería Real, reg. 3450, fol. $34 \mathrm{r}^{\mathrm{o}}-\mathrm{v}^{\circ}$; véase también Jordi RUBió I BALAgUER, Els autors clàssics a la biblioteca de Pere Miquel Carbonell, fins a l'any 1484, en Miscel-lània Crexells (Publicacions de la Fundació Bernat Metge, 1), Barcelona, 1929, pp. 205-222, aquí pp. 210-211 con n. 1.

10 Martin FrÜH, Antonio Geraldini... [ver n. 5], p. 19; John FloOD, Poets Laureate in the Holy Roman Empire: A bio-bibliographical Handbook, t. 1, Berlin y Nueva York, 2006, p. CXIV.

11 Martin FrÜH, Antonio Geraldini... [ver n. 5], pp. 18-50.

12 Ibid., p. 66.

13 Véase también Martin FRÜH, Antonio Geraldini en el mundo catalano-aragonés de su época: resultados de una tesis doctoral, en Tiziana DE ANGELIS (ed.), I Geraldini... [ver n. 2], pp. 65-69.

14 Jordi RUBIÓ I BALAGUER, Sobre Sal.lusti a la cancelleria catalana (segles XIV-XV), en ÍD., Humanisme i Renaixement (Biblioteca Abat Oliba, 86), Barcelona, 1990, pp. 271-295, aquí p. 294. 
En la Barcelona de los años setenta, Antonio Geraldini formaba parte del círculo de amistad del archivero real Pere Miquel Carbonell (1434-1517) y del poeta neolatino Jeroni Pau († 1497), estudiado por Mariàngela Vilallonga ${ }^{15}$. Dan testimonio de su red social los Carmina ad Iohannam Aragonum, dos libros de odas horacianas dedicados a una hija natural del rey Fernando el Católico. Estas odas, en su mayor parte seculares y escritas entre finales de los años 1470 y principios de los años 1480, se dirigen a personajes destacados de la Corona de Aragón, a colegas y amigos del poeta, y a miembros de su familia ${ }^{16}$. Entre ellas encontramos una poesía Ad eminentissimum regem Hispaniarum Ferdinandum Tertium de eius regnis ac uirtutibus, que eidem certius quam prophetarum et sibyllarum uersus amplissimum orbis imperium pollicentur, en la que Antonio Geraldini rechaza las profecías contemporáneas en torno al rey Fernando el Católico ${ }^{17}$.

Con el transcurso de los años, no tardaron en llegar algunas recompensas por parte de los reyes, en forma de prebendas eclesiásticas: probablemente en 1474, el rey Juan II de Aragón nombró a Antonio Geraldini abad comendatario del monasterio basiliano Santa Maria di Gala ${ }^{18}$, y en 1481, su hijo Fernando el Católico presentó a nuestro poeta como abad comendatario de S. Angelo de Brolo $^{19}$. Esas prebendas, situadas ambas en Sicilia, sirvieron de sedes stabiles para el humanista, como él explica en una oda dirigida a su compatriota italiano Francesco Vitale de Noya (carm. ad Ioh. 1,13) ${ }^{20}$ : Hispanos colimus lares, / Hispana cerere et cultibus utimur. / Tandem gratia principum / Haud errare uagas Thespiades sinens

15 Mariàngela Vilallonga, Feroni Pau: Obres, t. 1 (Autors Catalans Antics, 2), Barcelona, 1986, pp. 74-95; Martin FrÜH, Antonio Geraldini... [ver n. 5], pp. 115-123.

16 Martin FRÜH, Los Carmina ad Iohannam Aragonum del bumanista italiano Antonio Geraldini (m. 1489): reflexiones preliminares a una edición crítica, en Faventia, 22 (2000), pp. 141-144; edición crítica de las odas en Martin FRÜH, Antonio Geraldini... [ver n. 5], pp. 170-331.

17 Martin FrÜH, Profecía y realidad: una oda de Antonio Geraldini al rey Fernando el Católico, en Dietrich BRIESEMEISTER y Axel SCHÖNBERGER (eds.), De litteris Neolatinis in America Meridionali, Portugallia, Hispania, Italia cultis (Bibliotheca Romanica et Latina, 1), Fráncfort del Meno, 2002, pp. 47-67; Álvaro FERNÁNDEZ DE CÓRDOVA MIRALles, La emergencia de Fernando el Católico en la Curia papal: identidad y propaganda de un príncipe aragonés en el espacio italiano (1469-1492), en Aurora EGIDO y José Enrique LAPLANA (eds.), La imagen de Fernando el Católico en la Historia, la Literatura y el Arte. Fornadas Fernandinas desarrolladas en la Facultad de Filosofía y Letras de la Universidad de Zaragoza y en el Palacio Español de Niño de Sos del Rey Católico entre los días 7 y 9 de marzo de 2013, Zaragoza, 2014, pp. 29-81, aquí p. 57; Teresa JiMÉnEZ CALVENTE, Fernando el Católico: un héroe épico con vocación mesiánica, ibid., pp. 131-169, aquí pp. 138-139.

18 Martin FrÜH, Antonio Geraldini... [ver n. 5], p. 25. Fue en 1486 cuando Geraldini renunció a la abadía Santa María di Gala a favor de una canonjía en la catedral de Barcelona; ibid., pp. 45-46.

19 Ibid., pp. 39-40.

20 Ibid., p. 236; sobre Francesco Vitale di Noya, más tarde obispo de Cefalú, véase ibid., pp. 107-112; Álvaro FERNÁNDEZ DE CóRdOVA MIRALLES, Diplomáticos y letrados en Roma al servicio de los Reyes 
/ Iam sedes stabiles dedit / Non parcis et opes sumptibus annuas. / Et fauit facilis Deus / Amborum studiis, quando quidem sacris / Dantur sancta uiris loca. Así, dichas prebendas sentaron las bases para una rica producción literaria de nuestro poeta, y especialmente de versos religiosos en lengua neolatina. Sabemos que Antonio de Nebrija llama a ambos italianos omnium... qui apud nos peregrinati sunt... eruditissimi atque ingenio propemodum singulari ${ }^{21}$.

En el capítulo siguiente, presentaremos las poesías de la obra religiosa de Antonio Geraldini. Para comprender mejor las particularidades de esta obra, expondremos en primer lugar una breve visión panorámica de la situación literaria y concretamente de la poesía religiosa en lengua neolatina de la época que consideramos.

\section{LA POESÍA RELIGIOSA DE ANTONIO GERALDINI}

\section{II.1. Presupuestos: Antonio Geraldini y la poesía religiosa neolatina en la Península Ibérica}

Cuando Antonio Geraldini llegó al Reino de Aragón, en 1469, practicamente no había poesía religiosa en lengua neolatina en la Península Ibérica. Sí que existía una rica producción de versos cristianos en lenguas vernáculas ${ }^{22}$. Pero faltaban poesías latinas de estilo clásico; al menos antes de venir los humanistas Lucio Marineo Sículo, Aires Barbosa y Lucio Flaminio Sículo a Salamanca en los años 1480 o $1490^{23}$. Hay una excepción importante: el poeta barcelonés Jeroni

Católicos: Francesco Vitale di Noya, Juan Ruiz de Medina y Francisco de Rojas, en Dicenda. Cuadernos de Filología Hispánica, 32 (2014), pp. 113-154, aquí pp. 117-121.

21 Elio Antonio de Nebrija, Rerum a Fernando et Elisabe Hispaniarum felicissimis regibus gestarum decades duae, necnon belli Nauariensis libri duo, nunc secundo editi et exactiore uigilantia ad prototypi fidem recogniti et emendati, Granada, 1550, praefatio.

22 «La poesía religiosa, en tiempo de los Reyes Católicos, está representada especialmente por dos franciscanos, Fr. Íñigo de Mendoza y Fr. Ambrosio Montesino, y por un monje cartujo, Juan de Padilla» (Marcelino MENÉNDEZ PELAYo, Antología de los poetas líricos castellanos, t. 3, ed. por Enrique SÁNCHEZ REYES, [Obras completas de Menéndez Pelayo, 19], Santander, 1944, p. 41). En cuanto a la poesía vernácula en Cataluña, véase Josep Maria NADAL y Modest PraTs, Història de la llengua catalana, t. 2 (Estudis i documents, 34), Barcelona, 1996, pp. 273-301 y pp. 537-561.

23 Martin BiERSACK, Mediterraner Kulturtransfer am Beginn der Neuzeit. Die Rezeption der italienischen Renaissance in Kastilien zur Zeit der Katbolischen Könige (Mittelalter und Renaissance in der Romania, 4), Múnich, 2010, p. 106; Stefan SCHLELEIN, Cbronisten, Räte, Professoren. Zum Einfluß des italienischen Humanismus in Kastilien am Vorabend der spanischen Hegemonie (ca. 1450 bis 1527) (Geschichte und Kultur der Iberischen Welt, 6), Berlín, 2010, pp. 176-177; «Les poètes latins de 
Pau (†1497), «el primer humanista, no ja de Catalunya, sinó d’Espanya» (según nos dice Mariàngela Vilallonga ${ }^{24}$ ), y quien redactó un Hymnus panegyricus in festo diui Aurelii Augustini episcopi Hipponensis ${ }^{25}$. Sin embargo, en 1475 éste se trasladó a Roma donde iba a figurar como jurista al servicio de Rodrigo de Borja, el futuro papa Alejandro $\mathrm{VI}^{26}$.

En cuanto a Antonio Geraldini, en cambio, no cabe duda alguna que él ya había estudiado la poética latina de estilo clásico durante sus estudios humanísticos en la Italia de los años 1460. Por ejemplo, nuestro poeta conoció el uso neolatino de la oda horaciana en el círculo florentino de los Medici en los años sesenta $^{27}$. Ya en su Liber carminum ad magnificum Petrum Medicem Florentinum optimatem de re publica Florentina bene meritum constan dos odas horacianas de contenido espiritual ${ }^{28}$. Así, su estancia de aprendizaje en Florencia tuvo una influencia realmente importante sobre su obra lírica posterior. Más tarde, el poeta florentino Ugolino Verino (1438-1516) se mostró muy vinculado a su amigo Antonio Geraldini por su concepto común de un humanismo cristiano en la forma de la poesía clásica ${ }^{29}$, «une poésie d'esprit rigoureusement chrétien, qui mette

cette premiére période sont des hommes formés hors d'Espagne, en particulier en Italie...» (Juan Francisco ALCINA, Tendances et caractéristiques de la poésie hispano-latine de la Renaissance, en Augustin REDONDO [ed.], L'bumanisme dans les lettres espagnoles. XIXe colloque international d'études humanistes, Tours, 5-17 juillet 1976, [De Pétrarque à Descartes, 39], París, 1979, pp. 133-149, aquí p. 134); véase ÍD., La poesía latina del humanismo español: un esbozo, en Los humanistas españoles y el humanismo europeo. IV Simposio de Filología Clásica, Murcia 1990, pp. 13-30, aquí p. 13; cfr. Dietrich BRIESEMEISTER, Die neulateinische Lyrik in Spanien, en Manfred TIETZ (ed.), Die spanische Lyrik von den Anfängen bis 1870. Einzelinterpretationen, Fráncfort del Meno, 1997, pp. 255-269. Cfr. en general Teresa JimÉnez Calvente, Maestros de latinidad en la corte de los Reyes Católicos: ¿un ideal de vida o una vida frustrada?, en Nicasio SALVADOR MigUEL y Cristina MOYA GARCía (eds.), La literatura en la época de los Reyes Católicos (Biblioteca Áurea Hispánica, 52), Madrid, 2008, pp. 103-125.

24 Mariàngela VILALlonga, Feroni Pau... [ver n. 15], p. 18.

25 Mariàngela Vilallonga, Feroni Pau: Obres, t. 2 (Autors Catalans Antics, 3), Barcelona, 1986, pp. 174-187.

26 Mariàngela VILALlonga, La literatura llatina a Catalunya al segle XV. Repertori bio-bibliogràfic (Textos i Estudis de Cultura Catalana, 34), Barcelona, 1993, pp. 181-195. Sobre unos precursores de Jeroni Pau, de una calidad claramente menor, véase ibid., p. 14; de cuyas obras, todavía no se han estudiado el Hexameron sacrum seu de opere sex dierum de Mossèn Azà (ibid., p. 34) ni la Expositio siue ecphasis hymnorum tam de tempore quam de sanctis quibus ecclesia per anni circulum utitur de Guillem Morell (ibid., p. 162).

27 Martin FrüH, Antonio Geraldini... [ver n. 5], p. 174.

28 John Francis Chatterton RiCHARDS, Some Early Poems of Antonio Geraldini, en Studies in the Renaissance, 13 (1966), pp. 123-144, aquí pp. 132-135.

29 Francesco BAUSi, Geraldini, Antonio, en Francesco DELla CorTE y Scevola MARIOTTI (eds.), Enciclopedia Oraziana, t. 3, Roma, 1998, pp. 243-244, aquí p. 244; Martin FRÜH, Antonio Geraldini... [ver n. 5], p. 157. 
l'élégance du style au service de la vérité de la foi» ${ }^{30}$. En la Italia del Quattrocento, después de diversos debates sobre la compatibilidad entre arte poética y religión, nació una rica producción de poemas neolatinos de contenido espiritual, tal y como nos enseña el filólogo italiano Francesco Bausi en un estudio sucinto pero esclarecedor y fundamental ${ }^{31}$.

Sin embargo, Antonio Geraldini, cuando comenzó a cultivar la poesía religiosa en lengua neolatina de manera sistemática, ya había acabado su establecimiento definitivo en el Reino de Aragón. Sabemos que en 1476 o 1477 el papa Sixto IV nombró a Antonio Geraldini protonotarius apostolicus. Como clérigo, el humanista se consagró de manera intensificada a la poesía espiritual. Así que podemos observar un cambio en la vida de nuestro poeta: En la cuarta década de su existencia, dice él en un epigrama pospuesto a su Carmen bucolicum, se ha dirigido ad sacras res ${ }^{32}$. De este cambio procede la producción de su poesía cristiana, y concretamente de su Carmen bucolicum, de sus Fasti y de su Epodon liber ${ }^{33}$.

En el prefacio a su Carmen bucolicum, Geraldini expresa muy claramente su propósito $^{34}$ :

Si omnis humanae philosophiae ratio hoc imprimis iubet, ut quod quisque profitetur id praestet, nescio profecto..., quid meo muneri conuenientius rear quam res sacras scribere, qui sacris iam pridem initiatus protonotarii apostolici... titulo sum insignitus...; existimans... me non nibil luminis allaturum his, qui res Christianas Latine aut discere aut docere alios uoluerint. Quod secus ab aliis factitari audio, qui poesim magis imitatione quam arte sectantes ad gentilia relabuntur, nec quicquam nisi etbnicum aut profanum potius canere consueuerunt.

Según nos explica el filólogo alemán Lothar Mundt, Antonio Geraldini, al emplear el término ars, reclama para sí un arte de expresión y de creación poética

30 Attilio Bettrinzoli, Éloge des disciplines et divisions de la philosophie dans la littérature humaniste $d u$ Quattrocento, en Perrine Galand-Hallyn y Fernand Hallyn (eds.), Poétiques de la Renaissance. Le modèle italien, le monde franco-bourguignon et leur héritage en France au XVIe siècle (Travaux d'Humanisme et Renaissance, 348), Ginebra, 2001, pp. 3-29, aquí p. 28.

31 Francesco BAUsi, Poésie et religion au Quattrocento, ibid., pp. 219-238, aquí pp. 236-238.

32 Wilfred Pirt Mustard, The Eclogues of Antonio Geraldini (Studies in the Renaissance Pastoral, 4), Baltimore, 1924, p. 11.

33 Martin FrÜH, Antonio Geraldini... [ver n. 5], pp. 66-67.

34 Sigrun LeISTRITZ, Das «Carmen Bucolicum» des Antonio Geraldini. Einleitung, Edition, Übersetzung, Analyse ausgewählter Eklogen (Bochumer Altertumswissenschaftliches Colloquium, 61), Tréveris, 2004, p. 52. 
que se encuentra más allá de toda imitación y que es, por lo tanto, de una calidad mayor ${ }^{35}$.

En el epigrama ya mencionado ${ }^{36}$, queda patente también la amplitud de la obra religiosa escrita por nuestro poeta: Mox sacer ad sacras res mea uota tuli; / Namque elego fastos, lyricis sed uersibus hymnos, / Heroico cecini mystica sacra pede. $\mathrm{He}$ aquí los tres géneros literarios que empleó Geraldini al redactar sus versos religiosos: poesía bucólica, poesía lírica, y fastos. En 1484, compuso en la corte del arzobispo Alonso de Zaragoza, hijo natural del rey Fernando el Católico, su Carmen bucolicum (mystica sacra ${ }^{37}$ ), escrito en hexámetros (beroico... pede) y que en doce églogas presenta varias escenas del Nuevo Testamento. Su Epodon liber dedicado a la reina Isabel la Católica e impreso en Roma entre 1485 y $1487^{38}$ proyecta combinar unas paráfrasis de salmos en metros epódicos horacianos (lyricis... uersibus) con unos himnos sáficos a diversos santos (bymnos). Mientras que sus Fastorum libri Ferdinandi Catholici Hispaniarum regis (fastos), hoy perdidos, probablemente expusieron un calendario eclesiástico en dísticos elegíacos (elego).

Examinaremos en las siguientes páginas cómo Antonio Geraldini realiza su propósito docente en sus poemas de contenido espiritual, analizándoles obra por obra.

\section{II.2. El Carmen bucolicum}

\section{II.2.1. Antonio Geraldini y la transformación del género bucólico en su época}

Sin duda alguna, el Carmen bucolicum es la obra más impresa, leida y analizada de nuestro autor en la época moderna hasta nuestros días. Sin embargo, no se trata de la única ni de la primera obra bucólica salida de la pluma de Antonio Ge-

35 Lothar Mundt, Foachim Camerarius: Eclogae / Die Eklogen (NeoLatina, 6), Tubinga, 2004, p. XXVIII ( $\ll . .$. postuliert Geraldini mit dem Begriff ars eine poetische Ausdrucks- und Gestaltungskunst, die jenseits aller Nachahmung liegt und ebendeshalb einen höheren Rang beanspruchen kann»). Véase también Sigrun LeISTRITZ, Das «Carmen Bucolicum»... [ver n. 34], pp. 240-243.

36 Véase arriba, n. 32.

37 Es lo que dice Geraldini también en su Carmen bucolicum:... mystica sacra referto! (Sigrun LEISTRITZ, Das «Carmen Bucolicum»... [ver n. 34], p. 58). Esa iunctura se remonta a Ovidio (Ov., epist. 2,42).

38 Martin FrÜH, El Epodon liber de Antonio Geraldini, en Mariàngela VILALLONGA et al. (eds.), El cardenal Margarit i l'Europa quatrecentista. Actes del Simposi Internacional, Universitat de Girona, 14-17 de novembre de 2006 (Hispania Antigua, Serie Histórica, 3), Roma, 2008, pp. 193-203, aquí p. 195. 
raldini. Ya en su juventud, el cardenal Giacomo Ammanati Piccolomini (†1479) agradeció a Antonio pro bucolicis..., quae eiusmodi sunt, ut spem de te optimam praestent, añadiéndo no obstante algunas observaciones críticas en cuanto al contenido de esas poesías, hoy perdidas. Conocemos en cambio su égloga «familiar»o «heráldica», escrita hacia 1469, que en 124 hexámetros describe un encuentro de los hermanos Geraldini (es decir, Angelo, Giovanni, Bernardino, Battista y Geronimo) en la Amelia estival bajo un olivo, símbolo heráldico de la familia umbra ${ }^{39}$. Con todo, es el Carmen bucolicum la que representa la obra bucólica más larga de Geraldini, además de ser una verdadera obra renovadora e inspiradora para la literatura bucólica posterior.

Sabemos que la poesía bucólica, conocida como la poesía de los pastores, nació en la Grecia antigua. Sin embargo, en la época medieval y para los humanistas, importa muchísimo el modelo latino de la bucólica clásica confeccionado por el poeta romano Publio Virgilio Marón. Son características de ese modelo clásico la redacción en versos hexámetros, la relativa brevedad de las poesías, y la presencia de unos pastores, a menudo dialogantes ${ }^{40}$. A partir de las diez églogas de Virgilio, la bucólica latina en cuanto arte poetíca suele manifestarse en la recopilación compacta de varias poesías ${ }^{41}$. En la Antigüedad tardía, no tardaron en componerse las primeras églogas cristianas ${ }^{42}$.

En la Italia bajomedieval, la literatura bucólica afrontó un verdadero renacimiento. Ya en el siglo XIV, los poetas Dante Alighieri, Giovanni del Virgilio y Francesco Petrarca habían dado al género bucólico unos impulsos renovadores de inspiración humanista ${ }^{43}$. Para la bucólica religiosa posterior, sirve de modelo

39 Martin FrÜH, Antonio Geraldini... [ver n. 5], pp. 52-53. Véase la edición en William Leonard GRANT, A neo-latin 'beraldic' eclogue, en Manuscripta 4 (1960), pp. 149-163.

40 Michael VON ALBRECHT, Geschichte der römischen Literatur von Andronicus bis Boëthius, t. 1, 2. ${ }^{\text {a }}$ ed. revisada, Múnich, 1994, p. 527; Karl-Heinz STANZEL, Bukolik II. Lateinisch, en Hubert CANCIK y Helmuth SchneIder (eds.), Der Neue Pauly. Altertum, t. 2, Stuttgart y Weimar 1997, col. 833-835, aquí col. 833. Véase el análisis detallado en Bernd EFFE y Gerhard BINDER, Antike Hirtendichtung. Eine Einfübrung, 2. a ed. revisada, Düsseldorf y Zúrich, 2001, pp. 49-97.

41 Michael vON ALBRECHT, Geschichte... [ver n. 40], pp. 526-527.

42 Ibid., p. 527; Sigrun LeISTRITZ, Das «Carmen Bucolicum»... [ver n. 34], pp. 171-175; Gerhard BINDER, Vergil (Publius Vergilius Maro). B. Bucolica (Eklogen), en Brigitte EGGER y Christine WALDE, Der Neue Pauly. Supplemente, t. 7, Stuttgart y Weimar, 2010, col. 1074-1098, aquí col. 1077-1078; Bernd RoliNG, Von der donna zur madonna? Frauenfiguren in den Konversionseklogen Boccaccios, en Karl ENENKEL et al. (eds.), Iohannes de Certaldo. Beiträge zu Boccaccios lateinischen Werken und ibrer Wirkung (Noctes Neolatinae, 24), Hildesheim, Zúrich y Nueva York, 2015, pp. 197-218, aquí pp. 198-200.

43 Bernd EFFE y Gerhard BINDER, Antike Hirtendichtung... [ver n. 40], pp. 165-169; Sigrun LEISTRITZ, Das «Carmen Bucolicum»... [ver n. 34], pp. 175-176; Bernd Roling, Tod und Grabmal in der neulateinischen Eklogendichtung, en Graeco-Latina Brunensia 14 (2009), pp. 235-260, aquí pp. 241-242. 
el Carmen buccolicum de Giovanni Boccaccio, de $1372^{44}$. El primer poeta neolatino en describir una escena bíblica completa en una obra bucólica fue el italiano Francesco Patrizi da Siena (1413-1492) en su poema De natali Christi, de 1460 y dedicado al papa Pio II ${ }^{45}$. Podemos suponer que Antonio Geraldini, al componer su Carmen bucolicum, conocía ambas obras precedentes ${ }^{46}$.

No es extraño ver el entrelazamiento entre bucólica y Evangelio. En su égloga quarta, Virgilio ya había profetizado el retorno de la Edad de Oro, iniciado por el nacimiento de un niño divino. Además, cabe recordar la multitud de los escenarios pastorales que constan en el Nuevo Testamento: los pastores figurantes en la historia navideña, el papel de Jesucristo como «buen pastor», el ambiente pastoral de varias parábolas, etc. ${ }^{47}$. Como ya veremos, Antonio Geraldini trata de integrar algunos de esos escenarios en su Carmen bucolicum. Al componer esta obra, nuestro humanista es el primer poeta neolatino que crea una recopilación compacta de églogas neolatinas sobre temas bíblicos ${ }^{48}$. Podemos decir que en este Carmen bucolicum culmina la síntesis del pastoral con la poesía cristiana, forjando así la unidad de la forma bucólica con el contenido espiritual de la obra poética ${ }^{49}$.

Dicho Carmen bucolicum, dedicado a Alonso de Aragón (1469-1520) ${ }^{50}$, fue escrito en la corte arzobispal de este último, hijo natural del rey Fernando y arzobispo de Zaragoza desde 1478. Sabemos que Alonso, «verdadero impulsor y protector de una serie de manifestaciones que representan, muy cumplidamente, algo de lo mejor y más granado del esfuerzo cultural de su época» ${ }^{51}$, reunió en su corte a varios humanistas, entre ellos a Antonio Geraldini, quien también tuvo el

44 Bernd Roling, Von der donna... [ver n. 42], p. 211.

45 William Leonard GranT, Neo-Latin Literature and the Pastoral, Chapel Hill, 1965, pp. 259-260; Jozef IJSEWIJN y Dirk SACRÉ, Companion to Neo-Latin Studies, Part II: Literary, Linguistic, Philological and Editorial Questions (Supplementa Humanistica Lovaniensia, 14), 2. ed. revisada, Lovaina, 1998, p. 63.

46 Bernd Roling, Von der donna... [ver n. 42], p. 211, y Julio Alonso AsEnjo, Optimates letificare: la Egloga in Nativitate Christi de Joan Baptista Anyés o Agnesio, en Criticón, 66-67 (1996), pp. 307368, aquí p. 315.

47 William Leonard Grant, Neo-Latin Literature... [ver n. 45], pp. 258-259; Bernd Roling, Tod... [ver n. 43], pp. 246-247.

48 William Leonard GRANT, Neo-Latin Literature... [ver n. 45], p. 266; Bernd RoLING, Tod... [ver n. 43], pp. 249-250; Sigrun LeISTRITZ, Das «Carmen Bucolicum»... [ver n. 34], p. 185.

49 Bernd Roling, Tod... [ver n. 43], p. 249.

50 Sobre Alonso de Aragón, véase Martin FrÜH, Antonio Geraldini... [ver n. 5], pp. 76-79.

51 José Navarro Latorre, La politica cultural de Aragón en la época de Fernando II, en Cuadernos de Historia ferónimo Zurita, 39/40 (1981), pp. 135-150, aquí p. 139, véase también pp. 143-144, 147 150; Julio AlONSO ASENJo, Optimates... [ver n. 46], p. 315, n. 36. 
cargo de su «maestro» (preceptor) ${ }^{52}$. Este último dirigió al joven arzobispo dos odas en sus Carmina ad Iohannam Aragonum, la segunda de las cuales celebró a Alonso como mecenas, felicitándole quod bonarum artium studia sectetur et quod uera nobilitas in uirtute posita sit (carm. ad Ioh. 1,6) ${ }^{53}$. Más tarde, Alonso le encargó a Antonio que compusiese un epitafio para el inquisidor Pedro de Arbués, asesinado en $1485^{54}$.

El Carmen bucolicum, a su vez, nació del 1 de enero al 15 de febrero de 1484, lo que significa una producción media de 25 hexámetros al día, según calcula el filólogo norteamericano William Leonard Grant ${ }^{55}$; el manuscrito fue non una, sed duabus manibus exaratum, según nos dice el poeta mismo ${ }^{56}$. La impresión del incunable, de veinticinco hojas, se realizó en el año siguiente cura auctoris en el taller romano del impresor alemán Eucario Silber ${ }^{57}$.

La obra, que presenta varias escenas del Nuevo Testamento, consiste en doce églogas en versos hexámetros, con un total de 1155 versos. Examinaremos, a continuación, el contenido de estas églogas, poesía por poesía.

\section{II.2.2. La estructura y el contenido del Carmen bucolicum ${ }^{58}$}

La égloga primera (De Saluatoris natiuitate) tiene una extensión de 128 versos y expone un diálogo en la forma tradicional de la poesía bucólica ${ }^{59}$. En el frío invierno peninsular, hablan los pastores Mopsus et Lycidas ${ }^{60}$, es decir el poeta mismo y el arzobispo Alonso. Después de un largo inicio, que sirve también de introducción general a la obra entera, y que alaba al rey Fernando como «pastor

52 Miguel Ángel Parallés JimÉNeZ, La imprenta de los incunables de Zaragoza y el comercio internacional del libro a finales del siglo XV, Zaragoza, 2008, p. 634.

53 Martin FrüH, Antonio Geraldini... [ver n. 5], p. 78-79.

54 Daniel Rico CAMPS, La imágen de Pedro Arbués. Literatura renacentista y arte medieval en torno a don Alonso de Aragón, en Locus amoenus, 1 (1995), pp. 107-119.

55 William Leonard GRANT, Neo-Latin Literature... [ver n. 45], p. 266.

56 Es lo que escribe Antonio Geraldini en una carta al arzobispo de Santiago de Compostela Alfonso de Fonseca del año 1484; Madrid, Biblioteca Nacional de España, Incunables, 979.

57 Paola FARENGa, Le edizioni di Eucario Silber, en Maria CHIABÒ et al. (eds.), Roma di fronte all'Europa al tempo di Alessandro V. Atti del convegno, Città del Vaticano-Roma, 1-4 dicembre 1999 (Pubblicazioni degli archivi di Stato: Saggi, 68), Roma, 2001, pp. 409-439, aquí p. 416.

58 Véanse la edición en Sigrun LeISTRITZ, Das «Carmen Bucolicum»... [ver n. 34], p. 51-163, y los resúmenes ibid., pp. 197-205 y 215-238; William Leonard GRANT, Neo-Latin Literature... [ver n. 45], pp. 267-270.

59 Sigrun Leistritz, Das «Carmen Bucolicum»... [ver n. 34], p. 217.

60 Sobre el uso de nombres griegos en églogas navideñas, véase William Leonard GRANT, NeoLatin Literature... [ver n. 45], p. 259. 
que protege a sus ovejas» ${ }^{61} \mathrm{y}$ como expulsor de los musulmanes, se enumeran varias profecías del Antiguo y del Nuevo Testamento sobre la Navidad del Salvador. Acaba el poema en la mejor tradición bucólica, con una salida al pesebre de Belén para adorar al Niño.

La égloga segunda (De regum adoratione ad infantem Iesum), de 103 hexámetros, empieza con la aparición de la Estrella de Belén y con una larga descripción de la patria oriental de los Reyes Magos quienes representan aquí los tres edades de la vida humana. Los nombres de Gaspar, Melchor y Baltasar resultan ser «bucolizados» en Granicus, Mycon y Battus ${ }^{62}$. Dialogando, esos reyes-pastores cuentan sus sueños que anuncian la Navidad del Salvador, y deliberan sobre la elección de los regalos que van a entregar al Niño. El carácter bucólico de la salida final se manifiesta de doble manera: en la invitación a venerar al Niño y en la advertencia ante la Matanza de los Inocentes, proyectada por el rey Herodes.

La égloga tercera (Questus de filio amisso eorumque ac Iesus filii tandem reperti collocutio), de 79 hexámetros, presenta sobre todo un diálogo entre José y María, aquí llamada Marica según una figura virgiliana ${ }^{63}$. Al buscar a Jesús perdido, y encontrándole en el templo disputando con los doctores, éste calma a ambos.

La égloga cuarta (De baptismate et temptatione Saluatoris), de 67 versos, no se detiene tanto en describir el bautismo del Salvador (que se menciona sólo de manera muy breve), sino que cuenta la cuaresma y la tentación de Jesús. Este último figura como el pastor Yolas (conocido desde la bucólica virgiliana), mientras que al diablo se le llama Caronte (según el barquero antiguo de Hades). Cabe destacar la descripción de la salida del diablo, dirum stridensque gemensque, dejando un olor asqueroso $^{64}$.

Es en la primavera peninsular que la égloga quinta (De Christi miraculis), de 149 versos, presenta un diálogo entre el pastor Lynceus (es decir, el autor mismo), y otro pastor llamado Atys o Caelius, cuya identidad no queda clara: ¿sería uno de los alumnos de Antonio Geraldini6 ${ }^{65}$ ? Ambos rivalizan en enumerar los milagros de Jesús. Figura como árbitro un cierto Parthemius, quien bonus ingeniis

61 Es lo que subraya Teresa JimÉnEZ CALVENTE, Fernando... [ver n. 17], p. 140.

62 Julio Alonso AsEnjo, Optimates... [ver n. 46], p. 315, n. 35.

63 Sigrun LeISTRITZ, Das «Carmen Bucolicum»... [ver n. 34], p. 79, n. 150.

64 Bernd Roling, Zwischen epischer Theologie und theologischer Epik. Die Versuchung Christi in der lateinischen Bibeldichtung von Iuvencus bis Robert Clarke, en Frübmittelalterliche Studien 40 (2006), pp. 327-382, aquí p. 364.

65 Según Sigrun LeISTRITZ, Das «Carmen Bucolicum»... [ver n. 34], p. 200, podría tratarse de Alonso de Aragón. 
pastor fauet. Podemos suponer que este último es Bernat Margarit ${ }^{66}$, amigo catalán de Geraldini y desde 1479 obispo de Catania en Sicilia. En una oda dirigida al obispo (carm. ad Ioh. 2,14), el umbro usa igualmente el criptónimo Parthemius ${ }^{67}$. La competición finaliza con la sentencia de Parthemius, que los juzga ambos iguales en el canto. Figura como modelo de manera muy clara la égloga tercera de Virgilio, que igualmente aborda una competición pastoril.

La égloga sexta (De institutione sacramenti Eucharistiae), de 98 versos, no sólo cuenta la institución del sacramento de la Eucaristía, sino que en primer lugar describe la preparación de la Pascua. Intervienen Jesús y Cefas (es decir, Simón Pedro), quien al principio rehúsa el lavatorio. También se aborda el sentido de la Última Cena.

De passione Saluatoris trata la égloga séptima, de 125 hexámetros y en forma meramente monológica (loquitur auctor solus in toto carmine). Sin embargo, el poema empieza con una introducción alegorizante: los habitantes de un pueblo, llenos de envidia, matan a Daphnis, pastor afortunado. Sigue la descripción de la pasión de Jesucristo, desde la traición de Judas Iscariote hasta la crucifixión, y enriquecida por varias comparaciones procedentes del Antiguo Testamento. Mientras que todos los hombres llevan sus nombres propios (Judas, Malco, Caifás, Anás, Poncio Pilato, Barrabás), a Jesús se le llama Daphnis, aludiendo a la égloga quinta de Virgilio. Con esta artimaña literaria, Geraldini puso un punto final a un desarrollo literario que ya desde hacía siglos había intentado identificar al pastor virgiliano Daphnis con Jesucristo ${ }^{68}$.

En la égloga octava (De resurrectione Saluatoris), de 89 hexámetros, María Magdalena, llevando el criptónimo de la ninfa virgiliana Aegle, lamenta la desesperación de los discípulos después de la crucifixión, y busca alivio en la memoria del Salvador Bienhechor. Para consolarla, viene el Cristo Resucitado, en la forma del jardinero Acanthus, y le explica la resurrección, siguiendo el evangelio de San Juan. Tal y como nos muestra el filólogo alemán Bernd Roling, Geraldini realiza aquí una interpretatio christiana muy consecuente de la égloga quinta de Virgilio ${ }^{69}$.

La égloga novena (De ascensione Saluatoris) tiene una extensión de 72 hexámetros y presenta a los discípulos como pastores y agricultores (entre ellos encontramos a Tomás, llamado Didymus, y a Simón Pedro, llamado Cefas). Estos forman

\footnotetext{
66 Véase Martin FrÜH, Antonio Geraldini... [ver n. 5], pp. 128-132.

67 Ibid., pp. 132 y 323.

68 Bernd Roling, Tod... [ver n. 43], p. 250.

69 Ibid., p. 251.
} 
un coro que dialoga con Athanatus (es decir, el Cristo Ascendiente), despidiéndoles al subir al cielo.

La égloga décima (De emissione Sancti Spiritus), de 78 versos, cuenta los acontecimientos de Pentecostés. Los apóstoles aquí no llevan criptónimos bucólicos. Después del descendimiento del Espíritu Santo, ellos realizan, según la tradición patrística $^{70}$, la redacción del Credo Apostólico, cada uno añadiéndo dos versos, terminados siempre con una formula casi litúrgica: ergo uni ternoque Deo sit fausta potestas.

En la égloga undécima (De ultimo iudicio, quo iusti ab impiis distinguentur), de 68 versos, el poeta habla en forma de monólogo sobre el Juicio Final. Toman gran parte del poema (o sean 50 versos) los presagios y los sucesos terrenales en el Día del Juicio, quedando el resto para el transcurso del Juicio mismo.

En la égloga duodécima (De uita beata), de 99 hexámetros, se aborda el sentido de labor terrenal. El autor, bajo el criptónimo del pastor Lynceus, contesta a las preguntas de una persona que se llama Lycus y que es Hesperidum custos... agrorum et cultor. No es otro que Gaspar de Ariño, funcionario aragonés y secretari primer en la cancillería real en Barcelona. A éste dirigió Antonio Geraldini, en los Carmina ad Iobannam Aragonum, una oda horaciana (carm. ad Ioh. 1,9), tratando de la vida profesional de Gaspar (Ad Gasparem Arinnium regium Achatem poetarumque moecenatem de eius gloria laboribus permixta, et quod honores sine solicitudine esse cuiquam minime possunt) ${ }^{71}$. En la presente égloga, su criptónimo Lycus (derivado del griego antiguo lykos = lobo) alude a los tres lobos que constan en las armas de la familia Ariño. Lycus pregunta a Lynceus qué será la futura recompensa por su labor terrenal. Este último se muestra convencido de que la labor de Lycus será próspera y que sus huertos obtendrán una gran cosecha, ya que el rey Fernando, «nuestro Hércules» (Alcides noster) hace restablecer la Edad de Oro y expulsar a los musulmanes. A continuación, Lynceus describe con todo detalle la Vida Beata que seguirá después de la vida terrenal, finalizando así la obra entera.

\section{II.2.3. Visión de conjunto}

No cabe duda alguna que el Carmen bucolicum de Antonio Geraldini, desde el punto de vista formal, imita las églogas clásicas del poeta romano Virgilio. Lo que demuestran de manera muy clara el uso del hexámetro como metro empleado así como la relativa brevedad de las églogas (en Virgilio, entre 63 y 111 versos;

\footnotetext{
70 Sigrun LeISTRITZ, Das «Carmen Bucolicum»... [ver n. 34], p. 203, n. 375.

71 Martin FrÜH, Antonio Geraldini... [ver n. 5], pp. 101-104.
} 
en Geraldini, entre 67 y 149 versos) y la presencia del diálogo de unos pastores o agricultores en la mayor parte de las églogas. Se añade el escenario claramente pastoril en las églogas 1 y 12 , que sirven de marcos para la obra completa. No obstante, los investigadores filólogos desde siempre lamentan la falta casí absoluta de toda ambientación bucólica en otras partes de la obra. En cambio, se subraya el alto nivel de la latinidad de Geraldini y la recepción de varios poetas clásicos hasta la poesía cristiana tardo antigua y altomedieval, mientras que se critica el uso de la estructura narrativa ovidiana en lugar de la virgiliana, y sobre todo varios defectos en el desarrollo escénico del argumento ${ }^{72}$. Según observa Bernd Roling, Antonio Geraldini intenta realizar un distanciamiento clásico del escenario bíblico sin abandonar el relato del evangelio ${ }^{73}$. Así, Antonio Geraldini en su Carmen bucolicum se acerca de la épica bíblica, parafraseando el texto del Nuevo Testamento de manera poética clásica ${ }^{74}$, pero va más allá: según constata la filóloga alemana Sigrun Leistritz, nuestro poeta remodela el relato neotestamentario de manera bibliodramática, gracias a su propósito docente ${ }^{75}$. En la composición entera, se observan motivos recurrentes: las metáforas de la luz y de la oscuridad, del calor y del frío, la exhortación de alabar a Dios, el concepto del munus y la panegírica ${ }^{76}$.

Como hemos visto, en algunas églogas se encuentran varias reflexiones teológicas. Con eso, el Carmen bucolicum se halla en contraposición al Epodon liber de nuestro humanista, donde hay ausencia absoluta de comentarios exegéticos. De otra parte, observamos que Antonio Geraldini, sobre todo en las églogas 1 y 12, sitúa a sus protagonistas en la actualidad histórico-política de su tiempo, siguiendo así la tradición virgiliana ${ }^{77}$. Intervienen sus amigos aragoneses y catalanes que reflejan la historia de la Salvación y que glorifican al rey Fernando. Así, el Carmen bucolicum, impreso en Roma, pudo servir de medio propagandístico, divulgando la gloria de los futuros Reyes Católicos en Italia y en la Europa cristiana ${ }^{78}$.

72 Cfr. las referencias en Martin FrÜH, Antonio Geraldini... [ver n. 5], p. 54.

73 Bernd Roling, Zwischen epischer Theologie... [ver n. 64], p. 364.

$74 \ll$ Most of this [égloga 8], like a good deal of Geraldini's work, is little better than versified New Testament Narrative»; William Leonard GRANT, New Forms of Neo-Latin Pastoral, en Studies in the Renaissance 4 (1957), pp. 71-100, aquí p. 94. Véase también Bernd RoLING, Zwischen epischer Theologie... [ver n. 64], p. 363.

75 Sigrun LeISTRITZ, Das «Carmen Bucolicum»... [ver n. 34], p. 241.

76 Ibid., pp. 205-214.

77 Karl-Heinz STANZEL, Bukolik II... [ver n. 40], col. 833.

78 Véase abajo, cap. III; Teresa JimÉnEZ CALvENTE, Fernando... [ver n. 17], pp. 139-141. 


\section{II.2.4. La posteridad del Carmen bucolicum}

Con el transcurso de los años, el Carmen bucolicum deja sus huellas en la literatura europea ${ }^{79}$. Ya en 1484, Antonio Geraldini envió al arzobispo compostelano Alfonso de Fonseca (†1512) un manuscrito suyo (operis noui nedum non politi et elimati sed ne dolati quidem et uix signati exemplum archetipumque ${ }^{80}$ ), hoy perdido, pero cuya impresión salmatina ${ }^{81}$ fue realizada por este último en 1505 y celebrada por el humanista portugués Aires Barbosa (†1540): Erat boc dolendum poetam sacrum sacro plectro diuina resonantem et caelestia mysteria rustico sed tamen culto carmine canentem latere et in tenebris iacere... Ergo Geraldinus tuo munere nunc reuiuiscit, magnifice antistes ${ }^{82}$. En nuestros días, los investigadores españoles Marcial José Bayo y Julio Alonso Asenjo subrayan la importancia del Carmen bucolicum para la literatura bucólica peninsular del siglo XVI. Hay que mencionar la égloga In nativitate Christi del poeta valenciano Joan Baptista Anyés (1480-1533), a quien nuestro poeta «inspiró... no sólo el cultivo de la égloga y del hexámetro, sino sobre todo... la idea de reunir las verdades cristianas en un extenso poema» ${ }^{83}$, así como las églogas vernáculas del humanista Juan del Encina $(1468-1529 / 30)^{84}$, de igual modo influidos por el Carmen bucolicum geraldiniano. Cabe recordar que las églogas encinianas tuvieron gran influencia en el desarrollo del teatro peninsular ${ }^{85}$.

En cuanto a la divulgación europea del Carmen bucolicum, observamos que, dejando de lado una edición en Deventer $(1508)^{86}$, la mayor parte de sus reimpresiones se realizó en los países de lengua alemana: una en Pforzheim (1507),

79 Véase sobre lo que sigue Martin FrÜH, Antonio Geraldini: dimensiones europeas de un bumanista umbro, en Bullettino dell'Istituto storico italiano per il medio evo, 114 (2012), pp. 291-300, aquí pp. 298-300; Alejandro COROLEU, Printing and Reading Italian Latin Humanism in Renaissance Europe (ca. 1470-ca. 1540), Newcastle upon Tyne, 2014, pp. 59-60.

80 Madrid, BiblioteCa Nacional de EsPaÑa, Incunables, 979; véase Sebastião TaVAREs PINHO y Walter DE MedeIros, Aires Barbosa, Obra poética (Portugalliae Monumenta Neolatina, 13), Coimbra, 2013, p. 82, n. 145.

81 Frederick John NorTOn, La imprenta en España 1501-1520. Edición anotada, con un nuevo «Índice de libros impresos en España, 1501-1520», ed. por Julián Martín ABAD, Madrid, 1997, p. 269.

82 Sebastião TaVARES PinHo y Walter DE MEDEIROS, Aires Barbosa... [ver n. 80], p. 79.

83 Julio AlONSO ASENJO, Optimates... [ver n. 46], pp. 307-368, aquí p. 316 y n. 38; véase también pp. 314-316, 327-330, 344-345, 355, 362.

84 Marcial José BAYO, Virgilio y la pastoral española del Renacimiento (1480-1550), 2. ${ }^{a}$ ed., Madrid, 1970, p. 12. Véase también Ronald E. SURTZ, The Birth of a Theater. Dramatic Convention in the Spanish Theater from fuan del Encina to Lope de Vega, Madrid, 1979, pp. 29-30.

85 Aurelio Fuentes Rojo, Juan del Encina, Églogas, en Walter Jens (ed.), Kindlers Neues LiteraturLexikon, t. 5, Múnich, 1988, pp. 195-197, y Ronald E. SURTZ, The Birth... [ver n. 84], p. 9.

86 Wouter NijHOFf y Maria E. KRONENBERG, Nederlandsche Bibliographie van 1500 tot 1540, t. 1, La Haya, 1923, p. 353. 
tres en Leipzig (una en 1511 y dos en 1517), dos en Erfurt $(1512,1597)$, una en Viena (1513), una en Colonia (1520) y dos en Basilea $(1544,1546)^{87}$. Sabemos que en la Universidad de Erfurt, se empleó la impresión de 1512 para el uso de los estudiantes ${ }^{88}$. Según nos dice Sigrun Leistritz, la lectura del Carmen bucolicum ocurre en el contexto de la Contrarreforma Católica del siglo XVI ${ }^{89}$. Pero también algunos protagonistas de la Reforma Protestante, antes o después de sus conversiones, estudiaron las églogas de Antonio Geraldini. Así, Johannes Bugenhagen (1485-1558), el futuro reformador de Pomerania, enseña el Carmen bucolicum, siguiendo un comentario del humanista Johannes Murmellius, a sus alumnos en Treptow del Rega ${ }^{90}$. En nuestros días, Bernd Roling subraya la importancia de la obra geraldiniana para el género literario de la égloga navideña, muy popular en los círculos protestantes, y evoca las Eclogae (1576) del humanista alemán Gregor Bersmann (1538-1611) ${ }^{91}$. El poeta Martin Rheder, a su vez, no se arredra de cometer plagio, presentando como obra suya una versión «descatolizada» de la égloga 12 de Antonio Geraldini al consejo municipal protestante de Wernigero$\mathrm{de}^{92}$. Aún en el siglo XVII se nota la influencia del Carmen bucolicum, cuando el luterano danés Erik Eriksen Pontoppidan (1616-1678), más tarde obispo de Trondheim, escribe sus Bucolica sacra (1643) con referencia explícita al poeta umbro ${ }^{93}$. $\mathrm{Y}$ en las grandes bibliotecas alemanas siguieron estudiándose las ediciones de la obra geraldiniana, como lo vemos en la biblioteca ducal de Wolfenbüttel, donde

87 Martin FrÜH, Antonio Geraldini... [ver n. 5], p. 53; Sigrun LeISTRITZ, Das «Carmen Bucolicum»... [ver n. 34], pp. 34-43.

88 Jürgen LEONHARDT, Exegetische Vorlesungen in Erfurt 1500-1520, en Gerlinde HUBER-REBENICH y Walther LUDWIG (eds.), Humanismus in Erfurt (Acta Academiae Scientiarum, 7), Rudolstadt, 2002, pp. 91-109, aquí pp. 95, 99; véase también Marcial José BAYO, Virgilio... [ver n. 84], p. 17.

89 Sigrun LeISTRITZ, Das «Carmen Bucolicum»... [ver n. 34], pp. 246-247.

90 Otto Vogt, Dr. Fohannes Bugenhagens Briefwechsel, ed. por Eike Wolgast y Hans Volz, Hildesheim, 1966, pp. 2, 7. Según Anneliese BIEBER-WALLMANN, Fohannes Bugenhagen. Reformatorische Schriften, t. 1, Gotinga, 2013, p. 36, n. 5-6, podría tratarse de una confusión con el humanista italiano Angelo Poliziano.

91 Bernd Roling, Tod... [ver n. 43], p. 251 con n. 75. Véase también Lothar MUNDT, Simon Lemnius: Bucolica. Fünf Eklogen (Frühe Neuzeit, 29), Tubinga, 1996, pp. 48-50. Falta aún un estudio detenido sobre la recepción del Carmen bucolicum geraldiniano en la Europa del Renacimiento; cfr. otros ejemplos de églogas religiosas en William Leonard GRANT, Neo-Latin Literature... [ver n. 45], pp. 260-266 y 270-289.

92 William Leonard GRANT, Neo-Latin Literature... [ver n. 45], pp. 278-279; Sigrun LEISTRITZ, Das «Carmen Bucolicum»... [ver n. 34], pp. 271-276.

93 Jozef IJSEWIJn, Diffusion et importance historique de la littérature néo-latine, en Arcadia 4 (1969), pp. 179-198, aquí p. 186; Martin FrÜH, Antonio Geraldini... [ver n. 5], p. 54, n. 435. 
el subconrector protestante Johann Arnold Ballenstedt (1705-1788) sacó este libro el 30 de setiembre de $1740^{94}$. Sin embargo, se tuvo que esperar hasta el año 1924 para ver la primera edición crítica del Carmen bucolicum, realizada por el filólogo norteamericano Wilfred Pirt Mustard ${ }^{95}$.

II.3. El Epodon liber: lírica horaciana entre paráfrasis de salmos $y$ transformación de los Set goigs terrenals de la Verge ${ }^{96}$

\section{II.3.1. Introducción: la lírica horaciana en la obra de Antonio Geraldini}

Como ya hemos visto, en la posteridad Antonio Geraldini se percibe primordialmente como poeta de tradición virgiliana, gracias al gran éxito que tiene la recepción de su Carmen bucolicum. Al contrario de esta percepción moderna, nuestro humanista en su época pasa por ser un poeta lyricus ${ }^{97}$ y un Flacci emulus ${ }^{98}$.

Y efectivamente, una parte no menos importante de la obra poética de Antonio Geraldini son sus poesías en versos líricos según el modelo del poeta romano Quinto Horacio Flaco. Esta producción lírica se debe con toda probabilidad a la influencia de humanistas florentinos, e indirectamente a aquélla de Francesco Filelfo (1389-1481) ${ }^{99}$. Nuestro poeta es uno de los primeros autores neolatinos que llenan libros enteros con odas y epodos de estilo horaciano. Ya durante sus estudios en Florencia, a finales de los años 1460, Geraldini escribe dos libros de odas horacianas: el Liber carminum ad magnificum Petrum Medicem Florentinum optimatem de re publica Florentina bene meritum y el Sanctissimo domino nostro Paulo Secundo pontifici maximo liber carminum ${ }^{100}$. Y ya hemos mencionado sus otros dos libros de odas, redactados más tarde en la Península Ibérica y dedicados a Juana

${ }^{94}$ Mechthild RAABE, Leser und Lektüre im 18. Fabrbundert. Die Ausleibbücher der Herzog August Bibliothek Wolfenbüttel 1714-1799, t. 1, Múnich, 1989, p. 11.

${ }_{95}$ Wilfred Pirt MUSTARD, The Eclogues... [ver n. 32].

${ }^{96} \mathrm{El}$ análisis siguiente se basa en dos estudios míos: Martin FrÜH, El Epodon liber de Antonio Geraldini... [ver n. 38]; y Martin FRÜH, L'Epodon liber d'Antonio Geraldini: imitation d'Horace entre paraphrase de psaumes et transformation des Set goigs terrenals de la Verge, en Camenae 18 (2016), pp. 1-13; véase en internet: <http://saprat.ephe.sorbonne.fr/media/1dc249a2f64692b319e52e52 74dbe460/camenae-18-04-martin-fruh.pdf> [consultado el 9 de diciembre de 2016].

97 Así fue llamado por su amigo Michele Verino (1469-1487); véase Armando F. VERDE, Lo Studio Fiorentino 1473-1503, t. 3/2, Pistoia, 1977, p. 698.

98 Según el padre de Michele, Ugolino Verino (1438-1516); ms. FlorenCIA, BiblioteCA RiCCARDIANA, Ms. 915 , fol. $159 v^{\circ}$.

99 Martin FrÜH, Antonio Geraldini... [ver n. 5], p. 174.

${ }^{100}$ Ibid., pp. 14, 54, 55. 
de Aragón ${ }^{101}$. Hay que notar que con estos cuatro libros de odas, Antonio Geraldini emuló a Horacio en el número de volúmenes ${ }^{102}$.

Más precisamente, la imitación de Horacio en dicha obra lírica se extiende sobre todo al marco formal ${ }^{103}$. Geraldini hace uso de la métrica horaciana en su amplitud total, consagrando un interés especial al empleo temático de los metros diversos, tal y como lo hizo Horacio, y como lo haría más tarde el humanista italiano Pietro Crinito (1465-1507) ${ }^{104}$. Así no es extraño ver que Antonio Geraldini, según una expresión de Francesco Bausi, figura entre los «piu assidui e interessanti imitatori di H[oratius] dell'età humanistica» ${ }^{105}$.

Con todo, para completar el esquema imitativo de la obra lírica de Horacio, falta aún un libro de epodos ${ }^{106}$. Un tal Ad diuam Helisabet eminentissimam Hispaniarum reginam epodon liber procedente de la pluma de Antonio Geraldini fue impreso en Roma entre 1485 y 1487. Sin embargo, nuestro humanista ya lo había terminado por completo muy probablemente antes de su llegada a Italia en 1484/85 ${ }^{107}$. Al dedicar ese libro a Isabel la Católica, Geraldini también ocupa un vacío: después del Carmen bucolicum dedicado a Alonso de Aragón, los libros de odas dedicados a Juana de Aragón y los Fasti dedicados al rey Fernando el Católico ${ }^{108}$, la reina Isabel era la única persona importante de la corte real sin versos dedicados por Antonio Geraldini. Se observa además, que al contrario de las odas, que en su mayor parte son seculares, el Epodon liber de Geraldini tiene un carácter específicamente espiritual.

El incunable (GW 10668) ${ }^{109}$, de dieciséis hojas, procede del taller romano del impresor alemán Eucario Silber. La composición (lay-out) es muy parecida a

101 Véase arriba, cap. I.

102 Martin FrÜH, Antonio Geraldini... [ver n. 5], p. 56.

${ }^{103}$ ID., L'Epodon liber d'Antonio Geraldini... [ver n. 96], p. 2-3.

${ }^{104}$ ID., Antonio Geraldini... [ver n. 5], pp. 172-173; Jean-Louis CHARLET, Le choix des mètres dans les Poemata de Pietro Crinito, en Bibliothèque d'Humanisme et Renaissance, 67 (2005), pp. 7-26; véase también Martin FrÜH, Funus et eulogium: Antonio Geraldinis Ode zum Tode König Fohanns II. von Aragón, en Beate CZAPLA et al. (eds.), Lateinische Lyrik der Frühen Neuzeit. Poetische Kleinformen und ibre Funktionen zwischen Renaissance und Aufklärung (Frühe Neuzeit, 77), Tubinga, 2003, pp. 11-33.

${ }^{105}$ Francesco BAUSI, Geraldini... [ver n. 29], p. 244.

106 Podemos decir con seguridad que nunca no hubo un Epodon liber secundus de Antonio Geraldini, como lo suponen algunos investigadores; véase Martin FrÜH, Antonio Geraldini... [ver n. 5], p. 56.

107 Ibid., pp. 56-57, 199-201.

108 Ibid., pp. 59-60.

109 Gesamtkatalog der Wiegendrucke [GW], ed. por la DeUTSCHE STAATSBIBLIOTHEK, t. 9, Stuttgart y Berlín,1991, n. ${ }^{\circ}$ 10668. Sin embargo, la poesía introductoria dirigida a la reina Isabel se encuentra también en el codex R 12 sup. de la Biblioteca Ambrosiana en Milán; véase Martin FRÜH, Antonio Geraldini... [ver n. 5], p. 187. 
la del incunable que contiene los Carmina ad Iobannam Aragonum (GW 10666) ${ }^{110}$. Sin embargo, hay aún más erratas en el Epodon liber, e incluso falta un verso entero. Falta también la mención del autor; así que se supuso durante mucho tiempo que el autor del Epodon liber era el humanista italiano Baptista Mantuanus (1447-1516).

\section{II.3.2. La estructura y el contenido del Epodon liber}

Examinemos ahora la estructura y el contenido del Epodon liber. Se destacan muy claramente dos partes: una escrita en estrofas epódicas horacianas (epodos 1-10), y otra en estrofas sáficas (epodos 11-17). Se advierte que Geraldini crea un equilibrio entre ambas partes de su Epodon liber, atribuyéndoles a cada una 342 y 344 versos, respectivamente. Una disposición estructural muy parecida se encuentra en los mencionados Carmina ad Iobannam Aragonum de nuestro autor y será perfeccionada, en tiempos posteriores, por el humanista alemán Konrad Celtis (1459-1508) ${ }^{111}$. Se nota que las 17 poesías del Epodon liber coinciden con el número de los epodos de Horacio. Por lo demás, ese plano bipartito que Antonio Geraldini da a su Epodon liber refleja claramente la estructura de la obra epódica del Venusino, que a su vez es igualmente repartida en dos partes métricamente distintas (epodos 1-10: dísticos compuestos de un trímetro y un dímetro yámbicos; epodos 11-17: metros horacianos diversos ${ }^{112}$.

La primera parte del Epodon liber, redactada en las estrofas epódicas horacianas, consiste en la poesía dedicatoria a la reina Isabel (según el modelo de Horacio, quien dirige su epodo introductorio a Mecenas) y en nueve paráfrasis de salmos. Se trata de los siete salmos penitenciales (los salmos 6, 31, 37, 50, 101, 129, 142 de la Vulgata) así como los salmos 15 y 42 de la Vulgata. Geraldini usa dos veces el epodo yámbico (epodos 1 y 9), dos veces el epodo dactiloyámbico primero (epodos 5 y 7), dos veces el epodo dactiloyámbico segundo (epodos 2 y 6), una vez el epodo elegiambo (epodo 3), el epodo dactílico (epodo 4) y el epodo yambélego (epodo 10), añadiendo una poesía en trímetros yámbicos (epodo 8) ${ }^{113}$. La base textual de las paráfrasis oscila entre las dos traducciones realizadas por

110 Véase Martin FrÜH, Antonio Geraldini... [ver n. 5], pp. 189-191.

111 Ibid., pp. 171-172; Jürgen LEONHARDT, Metrische und formale Ordnungsprinzipien in den Odenbïchern des Konrad Celtis, en Ulrike AUHAGEN et al. (eds.), Horaz und Celtis (NeoLatina, 1), Tubinga, 2000, pp. 208-219.

112 Véase Ernst DoblHofer, Horaz in der Forschung nach 1957 (Erträge der Forschung, 279), Darmstadt, 1992, pp. 82-83.

113 Véase Federico CRUsIUs, Iniciación en la métrica latina, Barcelona, 1951. 
San Jerónimo: el Psalterium Gallicanum (según el texto de la Septuaginta) y el Psalterium iuxta Hebraeos ${ }^{114}$. En cuanto al léxico, podemos observar que aquí, como en las salmodias neolatinas posteriores, se hace uso de un vocabulario clásico y escogido en lugar del texto bíblico: Geraldini, a pesar de imitar la obra epódica de Horacio de manera rígida pero meramente formal, sí que emplea unas pocas palabras tomadas de la Vulgata, a las que prefiere, sin embargo, expresiones y iuncturae de procedencia clásica o poética. Es así que en sus paráfrasis de salmos encontramos alusiones a Cicerón, Lucrecio y Juvenal, pero a veces también a otros textos bíblicos, como al Libro de Isaías ${ }^{115}$.

No es ninguna sorpresa que Antonio Geraldini, representante del humanismo cristiano, opte por unas paráfrasis de salmos para componer esta primera parte de su Epodon liber. Nacidos entre 1100 y 200 a. C., los 150 salmos forman una parte integral de la Biblia hebrea ${ }^{116}$; en su traducción latina, realizada por San Jerónimo, los salmos van a ser el «libro de oraciones» de la iglesia cristiana, y aparecen en la misa romana así como en el breviario de los clérigos ${ }^{117}$. Desde el siglo XVI, es conocida la afición de la iglesia presbiteriana por los salmos, puestos en música en el Psautier huguenot (Salterio hugonote). Hay que notar que en nuestros días, la Iglesia Presbiteriana de Alemania ha publicado una versificación renovada de los 150 salmos sobre las melodías del Psautier buguenot del siglo XVI ${ }^{118}$.

Desde siempre, los salmos en cuanto la parte más poética de la Biblia, constituyeron un desafío para los poetas cristianos. En la Edad Media, normalmente no se trataba de transformar el texto bíblico en poesías latinas contemporáneas, sino de inventar nuevas poesías siguiendo el estilo de los salmos ${ }^{119}$. Sí que existe una paráfrasis de los salmos penitenciales de la pluma de Francesco Petrarca (probablemente del año 1348), pero está compuesta en prosa rítmica y no en versos clásicos ${ }^{120}$.

114 Véase Rolf PePPermüller, Psalmen, Psalter, A. Christliche Kirchen, en Norbert ANGERMANN et al. (eds.), Lexikon des Mittelalters, t. 7, Múnich, 1995, col. 296-297; Inka BACH y Helmut GALLE, Deutsche Psalmendichtung vom 16. bis zum 20. Jabrhundert. Untersuchungen zur Geschichte einer lyrischen Gattung (Quellen und Forschungen zur Sprach- und Kulturgeschichte der germanischen Völker, n. s., 95), Berlín y Nueva York, 1989, p. 55.

115 Véase Martin FrÜH, El Epodon liber de Antonio Geraldini... [ver n. 38], pp. 200-201.

116 Inka BACH y Helmut GALLE, Deutsche Psalmendichtung... [ver n. 114], p. 21.

117 Ibid., pp. 61-63.

118 Der Psalter, ed. por la EVANGELISCH-REFORMIERTE KiRCHE (SYNODE EVANGELISCH-REFORMIERTER KIRCHEN IN BAYERN UND NORDWESTDEUTSCHLAND), Gütersloh, 1997.

119 Inka BACH y Helmut GALLE, Deutsche Psalmendichtung... [ver n. 114], p. 62.

${ }^{120}$ Francesco Petrarca, Opere, ed. por Emilio Bigi / Giovanni PONTE, 4. ${ }^{a}$ ed., Milán, 1968, pp. 495 509 y pp. 1193-1195; Francesco Petrarca, Francisci Petrarcae psalmi et orationes. Francesco Petrarcas Psalmen und Gebete, lateinisch und deutsch, ed. por Erwin RAUNER, Augsburgo, 2004, pp. 10-33. 
Esta situación cambiará en el Renacimiento, puesto que las paráfrasis de los salmos fueron un asunto muy apreciado entre los poetas neolatinos, especialmente en el siglo XVI e inicios del siglo XVII. Según los investigadores Hugues Vaganay $^{121}$ y Johannes A. Gaertner ${ }^{122}$, Antonio Geraldini fue el primero en escribir tales paráfrasis poéticas. Con eso, nuestro humanista, muerto ya en 1488, sería el precursor de la rica producción sálmica del quinientos. Y no sólo en el género, sino también en la forma, Geraldini muestra tendencias «progresistas»: para realizar su paráfrasis de salmos, usa versos líricos y no el dístico elegíaco medievalizante, como será la práctica más usual en la primera parte del siglo XVI. Frente a la famosa pregunta de San Jerónimo: Quid facit cum psalterio Horatius? (Hier. epist. 22,30), nuestro humanista da el primer paso hacia una reconciliación de la lírica horaciana con los salmos. Esa reconciliación culminará 60 años más tarde, en la paráfrasis de salmos del poeta italiano Marco Antonio Flaminio (París, 1546) ${ }^{123}$, quien ganará la reputación de ser «el pionero en metrificar los Salmos a la manera horaciana» ${ }^{124}$. He aquí lo que dice José Valentín Nuñez Rivera sobre las vinculaciones de los salmos con la oda, las cuales, cum grano salis, podrían también aplicarse al epodo:

La paráfrasis del Libro de David [es decir, los salmos] en metro horaciano va a suponer la equiparación de ambos corpus poéticos, que mantienen entre sí evidentes y estrechas concomitancias. El salmo bíblico, como la oda clásica, es una composición destinada al canto o a la recitación con acompañamiento musical, e incluso con participación de la danza, identidad que se transluce, por ejemplo, en la etimología de sus términos, que apunta en última instancia a esa realización melódica. En el plano temático la semejanza es igualmente notable: si la oda se dedica fundamentalmente a la alabanza de los atletas vencedores y los héroes militares o a la reflexión de temas morales, el salmo se polariza asimismo en torno a dos núcleos genéricos equiparables: el himno a Yahvé y la lamentación o la súplica por la situación vital

${ }^{121}$ Hugues VAGANAY, Les traductions du psautier en vers latins au XVI siècle, Friburgo (Suiza), 1898, p. 6.

122 Johannes A. GaERTNER, Latin Verse Translations of the Psalms 1500-1620, en The Harvard Theological Review, 49 (1956), pp. 271-305, aquí pp. 293 y 300. Hay que notar que Gaertner, al indicar una edición «between 1497-1501..., Paris» del Epodon liber de Antonio Geraldini, confunde a nuestro poeta con el humanista holandés Aegidius Delphus (Gillis van Delft, †1524); véase Hugues VAGANAY, Les traductions... [ver n. 121], p. 6.

123 José Valentín NUÑEZ RIVERA, La versión poética de los salmos en el Siglo de Oro: vinculaciones con la oda, en Begoña LóPez BuENo (ed.), La oda. II Encuentro Internacional sobre Poesía del Siglo de Oro (Sevilla-Córdoba, 16-21 de noviembre de 1992), Sevilla y Córdoba, 1993, pp. 335-382, aquí p. 335 .

124 Ibid., p. 337. 
desfavorable. Hasta la misma estructura del Salterio, dividido en cinco libros, se adecúa perfectamente a los otros tantos que contienen los Carmina [y eso incluye los epodos] de Horacio ${ }^{125}$.

La variante epódica empleada por Antonio Geraldini subraya aún más el carácter dialógico de los salmos, y la forma dística de los epodos se corresponde perfectamente al parallelismus membrorum de los salmos ${ }^{126} .110$ años más tarde, el poeta suabo Sebastian Hornmold presentará una paráfrasis del salterio completo puris ac perpetuis iambis, es decir en el epodo yámbico (Tubinga, 1596) ${ }^{127}$. No sabemos si entre Geraldini y Hornmold hubo otros ensayos de poner los salmos en versos yámbicos. Desgraciadamente, faltan estudios detenidos para valorar el papel que tiene el Epodon liber de Antonio Geraldini dentro de la producción sálmica de los poetas neolatinos. De todas maneras, como en la mayor parte de las paráfrasis de salmos neolatinas, el propósito de Antonio Geraldini no es escribir comentarios teológicos de los salmos, sino dar testimonio de su saber poético y demostrar su «humanistic delight in literary skill» ${ }^{128}$. A ello se añade su intención pedagógica ya mencionada: como en su Carmen bucolicum y en sus Fasti, nuestro poeta presenta asuntos cristianos en una forma clásica para un uso escolar ${ }^{129}$. Además, la paráfrasis de los salmos penitenciales podría ofrecer una cierta satisfacción psicológica, gracias a su función consolatoria ${ }^{130}$.

Fijemos ahora nuestra atención en la segunda parte del Epodon liber. En esta parte, Geraldini presenta siete himnos en estrofas sáficas: uno sobre los Siete gozos de la Virgen María, otro sobre la asunción de la Virgen María, para concluir con himnos dedicados a diversos santos: Santa Ana, Santa Catalina (de Alexandria), Santa Ágata, San Juan Evangelista y Santiago, cuya posición en este libro seguramente no es casual: «Non per nulla il Geraldini fu in Spagna per molti anni», dice el investigador italiano Enrico Carrara ${ }^{131}$. En cuanto a la Virgen María, cabe destacar que Geraldini ya en su libro de odas a Piero de' Medici (c. 1468) compuso dos poesías, Ad diuam uirginem Mariam quae Florentiae nuntiata

125 Ibid., p. 336.

126 Sobre el parallelismus membrorum de los salmos, véase Inka BACH y Helmut GALLE, Deutsche Psalmendichtung... [ver n. 114], pp. 32-37.

127 Véase ibid., pp. 137-140.

128 Johannes A. GAERTNER, Latin Verse Translations... [ver n. 122], p. 274.

${ }^{129}$ Véase arriba, cap. II.1.

${ }^{130}$ Johannes A. GAERTNER, Latin Verse Translations... [ver n. 122], p. 278; véase también Inka BACH y Helmut GALLE, Deutsche Psalmendichtung... [ver n. 114], pp. 141-143.

131 Martin FrÜH, Antonio Geraldini... [ver n. 5], p. 56. 
nuncupatur, y Ad diuam uirginem Mariam quae Florentiae nuntiata cognominatur ${ }^{132}$. La presencia de Santa Ágata en el Epodon liber se explica por los apegos sicilianos de nuestro poeta, y la de San Juan Evangelista por ser el patrón de los escritores y así el del propio Geraldini. En el incunable, falta el título del himno a San Juan, por lo que los investigadores pensaron durante mucho tiempo que sólo contenía seis himnos ${ }^{133}$.

A primera vista, con esta segunda parte de su Epodon liber, nuestro humanista se inscribe en la larga tradición de la himnodia cristiana, que hunde sus raíces en la Antigüedad tardía, usando no obstante un latín clásico. De misma manera, el uso de la estrofa sáfica reanuda una tradición medieval que empieza sin embargo en el poeta tardo antiguo Prudencio ${ }^{134}$. Así que esas poesías, desde un punto de vista formal, pueden verse como himnos cristianos en forma clásica, o sea odae sacrae $^{135}$.

Sin embargo, no se trata aquí de un mero juego poético, intentando tan sólo un «syncrétisme désinvolte et esthétisant» ${ }^{136}$. Cuando la miramos de cerca, esta parte segunda del Epodon liber resulta ser un texto lleno de sorpresas. Efectivamente, nuestro poeta, al titular la primera de dichas siete poesías sáficas (epodo 11) Hymnus in septem gaudia diuae Virginis (GW 10668, fol. $9^{\mathrm{b}}-10^{\mathrm{b}}$ ), evoca claramente un género de la literatura catalana popular de su época: se trata de los Set goigs terrenals de la Verge Maria (los Siete gozos terrenales de la Virgen María). Los goigs son oraciones rimadas en lengua catalana, repartidas en estrofas regulares, a menudo en heptasílabos, y compuestas sobre melodías tradicionales ${ }^{137}$.

132 John Francis Chatterton RICHARDS, Some Early Poems... [ver n. 28], pp. 132-135.

133 Martin FrÜH, Antonio Geraldini... [ver n. 5], p. 56.

${ }^{134}$ Josef SzÖvÉRfFy, Die Annalen der lateinischen Hymnendichtung. Ein Handbuch, t. 1 (Die lyrische Dichtung des Mittelalters, 1), Berlín, 1964, p. 94.

135 Eckart SCHÄFER, Horatius Christianus. Zur Rezeption der Horazischen Dichtung bei den deutschen Neulateinern des 16. Fabrhunderts, en Jozef IJSEWIJN y Eckhard KESSLER (eds.), Acta Conventus Neo-Latini Lovaniensis. Proceedings of the First International Congress of Neo-Latin Studies, Louvain, 23-28 August 1971 (Humanistische Bibliothek, I 20), Múnich y Lovaina, 1973, pp. 509-515, aquí p. 511; Ann Moss, Latin liturgical bymns and their early printing history, 1470-1520, en Humanistica Lovaniensia, 36 (1987), pp. 112-137, aquí pp. 128-129.

${ }^{136}$ Francesco BAUSI, Poésie... [ver n. 31], p. 238.

137 Dominique DE CourCELLES, L'Écriture dans la pensée de la mort en Catalogne: les joies (goigs) des saints, de la Vierge et du Christ de la fin du Moyen Âge au XVIIIe siècle (Mémoires et documents de l'École de chartes, 35), París, 1992, p. 59; Josep Lluís MARTOS, El género popular de los goigs y foan Roís de Corella: La vida de la sacratíssima verge Maria y la Oració, en Carlos AlvaR et al. (eds.), Lyra mínima oral. Los géneros breves de la literatura tradicional. Actas del Congreso Internacional celebrado en la Universidad de Alcalá, 28-30 octubre 1998, Alcalá de Henares, 2001, pp. 85-97, aquí pp. 88-90. 
En su origen (probablemente en el siglo XII ${ }^{138}$ ), esas poesías, procedentes de un contexto litúrgico, no hicieron otra cosa que describir los Siete gozos terrenales de la Virgen, es decir la anunciación, el nacimiento del Señor, la adoración de los Reyes Magos, la resurrección del Señor, la ascensión del Señor, Pentecostés y la asunción de la Virgen ${ }^{139}$. Sin embargo, a finales del siglo XV, los goigs en cuanto género literario, situados en un ambiente parroquial, acabaron por independizarse $^{140}$. Así encontramos, más allá de las oraciones dedicadas a la Virgen, otras cuantas que se dirigen a santos diversos, narrando la vida terrenal (o bien los gozos terrenales ${ }^{141}$ ) de estos últimos.

En el origen del género literario de los goigs, había una poesía rimada en lengua latina, datada en el siglo XII y divulgada ampliamente en la Cataluña bajomedieval: Gaude, Virgo mater Christi, una poesía que, por su contenido, por su forma rimada y por el número y la disposición de sus estrofas (cada una describiendo exactamente un gozo), prefigura claramente los goigs posteriores en lengua catalana ${ }^{142}$. Como ya hemos demostrado ${ }^{143}$, Antonio Geraldini toma de este modelo latín algunas palabras significativas, una o dos por estrofa ${ }^{144}$. $\mathrm{Al}$ aplicar estas citas refinadas, nuestro poeta hace alusión directa a la corriente gogista de la Cataluña del siglo XV.

Sin embargo, el Hymnus in septem gaudia no sólo está influido por dicha poesía medieval; hasta los mismos goigs vernáculos dejan sus huellas en la oda entera. Lo que podemos constatar muy claramente cuando contraponemos, como ya lo hemos hecho ${ }^{145}$, dicho primer bymnus a un ejemplo de los goigs contemporáneos. La sola estructura de la poesía resulta estar fundamentalmente impregnado por aquélla de los goigs: la primera estrofa de la oda neolatina corresponde bien a la entrada inicial de los goigs, que suele ser igualmente de carácter paranético; además, ambas poesías presentan a continuación la descripción enumerativa de los

${ }^{138}$ Francesc Baldelló, Los 'goigs de la Mare de Deu', en Analecta Sacra Tarraconensia, 28 (1955), pp. 183-198, aquí p. 186.

139 Ibid., p. 184; Gemma AVENOZA, Un goig català inèdit de finals del s. XV o inicis del s. XVI: Verge, beneït fo, en Revista de Literatura Medieval, 5 (1993), pp. 37-46, aquí p. 42.

${ }^{140}$ Francesc BALDELló, Los 'goigs'... [ver n. 138], pp. 194-195; Dominique DE CoURCELLES, L'Écriture... [ver n. 137], p. 59.

${ }^{141}$ Ibid., p. 73-74; Josep Lluís MARTOS, El género... [ver n. 137], p. 89.

142 Dominique DE CourCELles, L'Écriture... [ver n. 137], pp. 51-53.

143 Martin FRÜH, L'Epodon liber d'Antonio Geraldini... [ver n. 96], p. 7.

144 Así, Geraldini emplea la misma técnica que utiliza en la primera parte del Epodon liber, donde él cita unas pocas palabras de la Vulgata, pero sin regularidad similar; véase Martin FRÜH, El Epodon liber de Antonio Geraldini... [ver n. 38], pp. 200-201.

145 Martin FRÜH, L'Epodon liber d'Antonio Geraldini... [ver n. 96], p. 7. 
siete gozos (cada gozo constituyendo una estrofa entera); finalmente, la última estrofa del bymnus, formando una oración (o bien la suplicación final) a la Virgen, equivale a la tornada final de los goigs ${ }^{146}$.

Geraldini, en lugar de recurrir a las anáforas incesantes empleadas habitualmente en los goigs para señalizar el principio de una nueva estrofa (y de un nuevo gozo), hace uso, por su parte, de conjunciones o de adverbios de tiempo en el primer verso de cada estrofa. Del punto de vista clásico, esta técnica da a la oda una estructura pesada, estéril y poco lírica pero adecuándose perfectamente a la corriente gogista del mundo catalán. De esta manera, Antonio Geraldini, siendo poeta neolatino, logra evocar, con los medidos que están a su disposición, el espíritu de los goigs vernáculos. Cuyo conocimiento, por parte de nuestro poeta, podemos tener por garantizado: «Era un género que inundaba la cultura catalana del siglo $\mathrm{XV} \gg^{147}$, lo que se manifiesta también en tantas y tantas representaciones iconográficas de los goigs ${ }^{148}$.

Pero podemos ir más allá; al titular esta oda Hymnus in septem gaudia diuae Virginis, Antonio Geraldini prepara el terreno para toda la segunda parte, cuyas siete poesías coinciden, por lo demás, con el número de los gozos terrenales de la Virgen. Se nota muy rápido que todos los bymni que siguen (epodos 12-17) están también impregnados por la estructura narrativa de los goigs. Lo que vale ya para la poesía siguiente, el Hymnus in assumptionem beatae Virginis (GW 10668, fol. 10b-11b). Si bien tales himnos latinos, consagrados a la asunción de la Virgen, son muy numerosos en la Baja Edad Media; en estos casos, se trata de poesías laudatorias, que reservan la mayor parte de sus versos a la alabanza de la Virgen. Sin embargo, Geraldini, por su parte, sirviéndose de la Legenda aurea y observando un orden rigurosamente cronológico, cuenta los acontecimientos que nos conducen a la asunción de la Virgen. Y este estilo descriptivo se manifiesta en todos los hymni ulteriores del Epodon liber. Nuestro poeta no hace otra cosa que narrar las vidas de los santos (lo que admite, por negación, en el epodo 16 dirigido a San Juan: Nescit bumano tua mira cantu / Vita referri ${ }^{149}$ ), consagrando a menudo una estrofa completa a un cierto acontecimiento hagiográfico. No hace falta ir muy lejos para encontrar un modelo literario. Lo que nos explica la investigadora fran-

146 Para la estructura de los goigs, véase Pep VILA, Els set goigs terrenals de la Verge Maria de la catedral de Girona, en Annals del Institut d'Estudis Gironins, 44 (2003), pp. 179-184, aquí p. 180.

147 Josep Lluís MARTOS, El género... [ver n. 137], p. 91.

148 Para las representaciones iconográficas de los goigs, véase Francesc BaLdELló, Los 'goigs'... [ver n. 138], pp. 191-192; véase también Pep VILA, Els set goigs... [ver n. 146], pp. 180-181.

149 Martin FRÜH, L'Epodon liber d'Antonio Geraldini... [ver n. 96], p. 8. 
cesa Dominique de Courcelles en su monografía sobre los goigs: es precisamente la manera de tratar los asuntos hagiográficos que marca la diferencia esencial entre los goigs catalanes y los himnos latinos medievales, estos últimos resultando ser predominantemente laudatorios, mientras que en los goigs impera el aspecto narrativo de manera muy clara ${ }^{150}$. A esto se suma el hecho que cada bymnus geraldiniano empieza con una estrofa parenética y se termina por una suplicación final. Es así como se perfecciona la forma gogista dada por Antonio Geraldini a la segunda parte, cuyo estrofismo, en contraposición a los dísticos en la primera parte del Epodon liber, se explica también por la influencia de los goigs $s^{151}$.

$\mathrm{Al}$ optar por la variante gogista, nuestro poeta subraya el aspecto narrativo de sus hymni neolatinos dirigidos a los santos. Por este detalle literario, Geraldini se halla en contraposición a su amigo florentino Ugolino Verino, cuyos himnos neolatinos se muestran principalmente inspirados por las laude italianas, de carácter meramente laudatorio ${ }^{152}$. Por otro lado, nuestro humanista se aleja de su propia práctica lírica de antaño, cuando compuso, en su libro de odas a Piero de' Medici, otras dos odas dirigidas a la Virgen, menos narrativas que encomiásti$\operatorname{cas}^{153}$.

\section{II.3.3. Conclusiones}

Después de haber analizado el conjunto del Epodon liber de Antonio Geraldini, podemos sacar tres conclusiones.

En cuanto a la métrica de sus epodos, Antonio Geraldini se presenta como poeta de tradición horaciana, al componer versos epódicos y estrofas sáficas. Se trata de una imitación muy rígida, pero meramente formal.

Por el contenido de su obra epódica, nuestro poeta se muestra claramente como poeta cristiano. Efectivamente, al componer poesías cristianas sobre dichos metros horacianos, Antonio Geraldini sobrepasa el límite de la mera imitación del Venusino y marcha más allá. Así que, ante este contenido del Epodon liber, nos preguntamos cuál era la intención de nuestro humanista al combinar dos partes diferentes -las salmodias epódicas y los himnos sáficos- en un solo libro. La respuesta es fácil de deducir: sabemos que los salmos penitenciales aparecen

${ }^{150}$ Dominique DE COURCELLES, L'Écriture... [ver n. 137], pp. 85-86.

${ }_{151}$ Para el estrofismo de los goigs, véase Josep Lluís MARTOS, El género... [ver n. 137], pp. 88-89.

152 Nikolaus THURN, Neulatein und Volkssprachen. Beispiele für die Rezeption neusprachlicher Literatur durch die lateinische Dichtung Europas im 15.-16. 7h. (Humanistische Bibliothek I, 61), Múnich, 2012, pp. 106-109 y 113-114.

153 John Francis Chatterton RICHARDS, Some Early Poems... [ver n. 28], pp. 132-135. 
regularmente en los libros de horas de la Baja Edad Media. Vale lo mismo para la letanía de los santos y también para los Siete gozos de la Virgen ${ }^{154}$. Todos estos textos se encuentran, en forma lírica, en el Epodon liber de Antonio Geraldini. Así podemos concluir que nuestro poeta, al combinar los salmos con los himnos a los santos y con los Siete gozos de la Virgen en su Epodon liber, presenta a la reina Isabel un libro de horas de carácter específicamente humanista ${ }^{155}$.

Sin embargo, nuestro poeta no se detiene allí, limitándose en presentar asuntos cristianos en forma clásica; él va más allá, al demostrar también su capacidad de integrar una corriente literaria catalana en una obra lírica refinada en lengua neolatina. Antonio Geraldini contesta así, una vez más, a las tendencias vernáculas contemporáneas y se muestra atento observador de la vida literaria de su época, tal y como ya lo había hecho en sus Carmina ad Iohannam Aragonum, cuando en una oda al rey Fernando el Católico supera, con los armas de un humanista, las profecías en torno a los Reyes Católicos ${ }^{156}$.

Cuando nos preguntamos si estas influencias populares representan un caso único en la literatura culta de la época humanista, la respuesta es negativa: «La impregnación de los poetas cultos por temas y esquemas métrico-estróficas de carácter popular es una evidencia más que demostrada» ${ }^{157}$. Así, Antonio Geraldini no fue el primer autor culto en inspirarse por los goigs. Ya en la obra de Joan Roís de Corella (1435-1497), poeta en lengua vernácula, se encuentran dos poesías, cuyo contenido y forma resultan estar sumamente impregnados por los goigs populares ${ }^{158}$. Y Antonio Geraldini, ya antes de redactar su Epodon liber, no se arredra al inspirarse por corrientes literarias vernáculas. Es así que, como nos enseña el filólogo alemán Nikolaus Thurn, varias odas neolatinas de los Carmina ad Iobannam Aragonum resultan estar influidas por géneros poéticos vernáculos, entre ellos la caccia italiana, el romancero castellano o el tautograma catalán ${ }^{159}$. Más tarde, el poeta portugués Diogo Pires (1517-1599) realizará una adaptación

154 Victor LeroquaIs, Les livres d'heures manuscrits de la Bibliothèque Nationale, t. I, París, 1927, pp. XIV-XL.

155 Para la religiosidad de la reina Isabel, véase Tarsicio DE AZCONA, Isabel la Católica. Estudio crítico de su vida y de su reinado, 3. . ed. actualizada (BAC, 237), Madrid, 1993, pp. 380-390; Álvaro FERNÁNDEZ DE CóRdova Miralles, Isabel la Católica. La fe de una reina, en Pablo PÉREZ LóPeZ (ed.), Personajes de fe que hicieron historia, Madrid, 2014, pp. 15-45. ÍD., La emergencia... [ver n. 17], p. 74, subraya el hecho que el Epodon liber «apuntala la docta pietas de la reina en un momento en que su política religiosa y cultural comenzaba a dar sus primeros frutos».

156 Martin FrÜH, Profecía... [ver n. 17].

${ }^{157}$ Josep Lluís MARTOS, El género... [ver n. 137], p. 94.

158 Ibidem.

159 Nikolaus THURN, Neulatein... [ver n. 152], pp. 227-238. 
neolatina de una serranilla iberorrománica ${ }^{160}$. Podemos concluir que Antonio Geraldini, según las palabras de Nikolaus Thurn, fue «una figura extraña, pero posiblemente no escasa ${ }^{161}$ dentro de la literatura humanista, adaptando varios géneros literarios vernáculos a su poesía neolatina y cristiana.

\section{II.4. Los Fasti (Fastorum libri) de Antonio Geraldini: aproximaciones a una obra perdida}

Hemos visto en el epigrama pospuesto a la impresión de su Carmen bucolicum (1485) que Antonio Geraldini menciona sus Fasti: Namque elego fastos... cecini $^{162}$. Desgraciadamente, estos Fasti no se han conservado. Sólo tenemos unos testimonios escasos en otros textos escritos por Geraldini o por sus amigos.

De dicha cita podemos concluir que los Fasti se redactaron en versos elegíacos, es decir en dísticos compuestos cada uno de un hexámetro y un pentámetro. Lo que confirma otra mención de los Fasti geraldinianos, en la Oratio ante el papa Inocencio VIII (1486): ...in fastorum meorum uolumine, quod nuper elegiaco uersu composui... ${ }^{163}$. Además, en ambas citas precedentes, de los años 1485 y 1486, queda patente que Antonio Geraldini tenía sus Fasti casi acabados durante su embajada italiana (1485-1487). Aparentemente, intentaba realizar su publicación en Roma, en el caso de que tuviera éxito con su Carmen bucolicum: Quod si probari sensero, statim hymnos nostrorum heroum [es decir, el Epodon liber] et fastos, quos paulo ante incepi, absoluam ${ }^{164}$. Sin embargo, al morir nuestro poeta en 1488, su amigo florentino Ugolino Verino tuvo que constatar: Ille enim fastorum pulcherrimos libros scribebat, necdum absoluerat ${ }^{165}$. Según una biografía anónima sobre nuestro humanista, la obra fue dedicada al rey Fernando (Fastorum libri Ferdinandi Catholici Hispaniarum regis) ${ }^{166}$.

Se trata, pues, de una poesía escrita en dísticos elegíacos y compuesta de varios libros. No cabe duda alguna que Antonio Geraldini, al redactar esta obra,

160 Tobias LEUKER, Una serranilla en latin: la adaptación de un tipo de poesía iberorrománico en una elegía de Diogo Pires, en Dicenda. Cuadernos de Filología Hispánica, 32 (2014), pp. 251-263.

161 «... eine seltsame, aber möglicherweise nicht seltene Erscheinung...» (Nikolaus THURN, Neulatein... [ver n. 152], p. 240).

162 Véase arriba, cap. II.1.

163 Martin FRÜH, Antonio Geraldini... [ver n. 5], p. 59, n. 488.

164 Sigrun LeISTRITZ, Das «Carmen Bucolicum»... [ver n. 34], p. 52.

165 ms. FLORENCIA, BIBLIOTECA RICCARDIANA, Ms. 915 , fol. $159 \mathrm{v}^{\circ}$.

166 ms. Roma, BibliotheCA Apostolica VatiCANa, Barb. lat. 2312, fol. 120ro . 
siguiera el modelo formal del poeta romano Publio Ovidio Nasón, creador del género literario de los Fasti ${ }^{167}$. Cuyos seis libros de Fasti, de impregnación didáctica y compuestos en dísticos elegíacos, explicaron los primeros seis meses del calendario romano pagano, mientras que nunca se escribieron los seis libros restantes ${ }^{168}$. Antonio Geraldini, en la inscripción de su medalla acuñada durante su embajada italiana, muestra su clara intención de equipararse con el poeta romano: ANTONIVS GERALDINVS... FASTORVM VATES ${ }^{169}$, retomando así una autodefinición ovidiana ${ }^{170}$. Sin embargo, no cabe duda alguna de que hubo grandes diferencias entre ambas obras en cuanto al contenido, ya que los Fasti ovidianos estaban consagrados a la explicación de un calendario pagano. Así, nos preguntamos cuál era el tema de los Fasti de nuestro humanista.

Durante mucho tiempo, los investigadores trataron de establecer un vínculo entre la redacción de los Fasti y el cargo de cronista real que ocupó Antonio Geraldini ${ }^{171}$. Sin embargo, los chronistes del rey don Ferrando, qui'n són bé pagats (según escribió el archivero real Pere Miquel Carbonell ${ }^{172}$ ), solían tomar nota de los acontecimientos actuales y expresarse en prosa (castellana, catalana o latina). En cuanto a Geraldini, podemos suponer que con toda probabilidad intentó transformar el género poético de los Fasti ovidianos, adaptándolo al cristianismo, como lo hicieron otros poetas neolatinos de su época ${ }^{173}$. Por ejemplo, el humanista italiano Giovanni Battista Spagnoli (Baptista Mantuanus, 1447-1516) en sus Fastorum libri duodecim describe las fiestas de los santos, basándose en la Legenda aurea ${ }^{174}$. De ahí, no es difícil concluir que nuestro poeta se refiere a sus Fasti cuando, al enviar su Carmen bucolicum al obispo compostelano Alfonso de Fonseca en 1484, anuncia la redacción de otra obra religiosa: ....habebit [amplitudo

167 Edward John Kenney, Ovidius Naso, Publius, en Hubert CANCIK y Helmuth SCHNEIDER (eds.), Der Neue Pauly. Altertum, t. 9, Stuttgart, 2000, col. 110-119, aquí col. 114.

168 Ibid., col. 114-116.

169 Martin FrÜH, Antonio Geraldini... [ver n. 5], p. 47.

170 Véase Geraldine HerberT-Brown, Ovid and the Fasti. An Historical Study, Oxford, 1994, p. 6.

171 Véase Martin FrÜH, Antonio Geraldini... [ver n. 5], pp. 59-62.

172 Ibid., p. 62, n. 517.

173 Paul Gerhard SCHMIDT, Transformation und Substitution von Ovids Fasten im 16. und 17. Fabrhundert, en Rhoda SCHNur (ed.), Acta Conventus Neo-Latini Hafniensis. Proceedings of the Eighth International Congress of Neo-Latin Studies, Copenhagen, 12-17 August 1991, Binghamton (NY), 1994, pp. 891-898; John Miller, Ovid's Fasti and the Neo-Latin Christian Calendar Poem, en International Fournal of the Classical Tradition, 10 (2003), pp. 173-186; Angela FrITSEN, Antiquarian Voices: The Roman Academy and the Commentary Tradition on Ovid's Fasti, Columbus, 2015, pp. 165-166.

174 Véase Hans TRÜMPY, Die Fasti des Baptista Mantuanus von 1516 als volkskundliche Quelle (Bibliotheca Humanistica et Reformatorica, 26), Nieuwkoop, 1979, pp. 8-10. 
tua] non multo post aliorum operum exempla, si non saltem elegantiora quidem non minus religiosa. Coepi enim aliud opus de cultu et obseruatione sacrorum rituum et temporum $^{175}$. De ese modo, sus Fasti serían una adaptación cristiana del calendario poético de Ovidio, explicando el año litúrgico y los ritos del culto eclesiástico. Además, como podemos leer en la Oratio de Antonio Geraldini, forma parte de sus Fasti una historia de la Salvación, abordando la sustitución del imperio Romano por el Christianum imperium (es decir, la Iglesia Católica): Quod autem illud Romanorum buius Christiani imperii preludium fuerit ac plane presagium, facillime probari potest... Vero... eadem fere omnia... in fastorum meorum uolumine... commodius latiusque explicata sunt ${ }^{176}$.

\section{CONCLUSIÓN: LAS FUNCIONES DE LA POESÍA RELIGIOSA DE ANTONIO GERALDINI ${ }^{177}$}

Si consideramos la obra religiosa que Antonio Geraldini escribió en la época fernandina, podemos observar en primer lugar su originalidad poética. Ésta se muestra en el vínculo que encontramos entre la forma clásica y el contenido espiritual de sus poesías. Según parece, nuestro humanista, al componer su Epodon liber, es el primer poeta neolatino en redactar unas paráfrasis de salmos en versos líricos horacianos. Su Carmen bucolicum, a su vez, resulta ser la primera recopilación compacta de églogas neolatinas sobre unos temas bíblicos, imitada más tarde por otros tantos poetas. Así, Geraldini logra obtener su doble propósito, ser docente y en la forma literaria clásica y en el contenido espiritual. Desde el punto de vista teológico, este contenido se limita a la enseñanza de los relatos bíblicos o hagiográficos. Cuando buscamos eventuales reflexiones teológicas pronunciadas por nuestro poeta, tenemos que constatar una falta absoluta en el Epodon liber mientras que observamos una presencia mínima en el Carmen bucolicum.

Sin embargo, nuestro humanista no se detiene ahí. Funcionario de la Corona de Aragón y atento observador de los desarrollos políticos así como de la vida literaria de su época, logra situar sus poesías espirituales en un contexto históricocultural hispánico. Así, podemos observar las grandes huellas que el género lite-

\footnotetext{
175 MAdRID, BIBLIOTECA NACIONAL DE ESPAÑA, Incunables, 979.

176 Véase Martin FrÜH, Antonio Geraldini... [ver n. 5], p. 60, n. 491.

177 Cfr. en general el estudio fundamental de Gerlinde Huber-Rebenich, Neue Funktionen der Dichtung im Humanismus?, en Thomas MAISSEN y Gerrit WALTHER (eds.), Funktionen des Humanismus. Studien zum Nutzen des Neuen in der bumanistischen Kultur, Gotinga, 2006, pp. 49-75.
} 
rario de los goigs catalanes deja en los himnos del Epodon liber. Y en el Carmen bucolicum, Antonio Geraldini hace actuar a unos amigos suyos hispánicos, situando así partes del escenario bíblico en la actualidad peninsular. De ahí se explica que nuestro umbro, en su discurso de obediencia ante el papa Inocencio VIII, pudo decir: Ego licet natione sim Italus, tamen Hispanus sum educatione ${ }^{178}$.

Dicha actualidad de su poesía espiritual nos lleva a la última función que se puede atribuir a la producción literaria de Antonio Geraldini, y eso es el valor propagandístico de sus obras. Hemos visto que en el Carmen bucolicum se glorifica al rey Fernando como «nuestro Hércules», mientras que en la poesía introductoria del Epodon liber, se compara a la reina Isabel con varias diosas antiguas, superando cada una en la virtud que es propia de ella. Y no falta aquí la anunciación de la Edad de Oro, profetizada por Sibila y varios poetas: Iam tempus instat proditum / Modis Sybillae et poetarum cantibus, / Quo mundus omnis audiat, / Edicta regum fulminantis Hesperi, / Quo iunctus est leonibus / Ales Iouis ${ }^{179}$, cum Ferdinandus imperet / Helisabet cum coniuge ${ }^{180}$. No es casualidad que ambas obras espirituales, así como los Carmina ad Iohannam Aragonum y la Oratio ante el papa Inocencio VIII (donde Geraldini «presenta a los monarcas bajo un imponente modelo clásico que opera bajo coordenadas cristianas» ${ }^{181}$ ), fueran impresas en Roma, capital de la Europa católica. La publicación romana de esas poesías geraldinianas intenta lograr dos objetivos: equipararse con la producción neolatina de los humanistas italianos ${ }^{182}$, empleando técnicas literarias refinadas y metros líricos difíciles, y al mismo tiempo contribuir a «una campaña publicitaria de la familia real en la ciudad pontificia», según los estudios recientes de Álvaro Fernández de Córdova Miralles $^{183}$. Esa orquestación propagandística se completa por los Fasti espiri-

178 Martin FrÜH, Antonio Geraldini... [ver n. 5], p. 66. Véase también ÍD., Antonio Geraldini: dimensiones... [ver n. 79], pp. 294-295, 297.

179 Sobre esta alusión heráldica, empleada también en la Apostrophe ad exleges Mauros de Antonio Geraldini y ya antes (c. 1480) por su amigo Jeroni Pau, véase Álvaro FERNÁNDEZ DE CóRDOVA MiRALleS, La emergencia... [ver n. 17], p. 51, n. 80; Edoardo D'ANGELO, L'Apostrophe ad exleges Mauros di Antonio Geraldini d'Amelia: poesia e diplomazia nell'Europa della Reconquista, en Bullettino dell'Istituto storico italiano per il medio evo, 113 (2011), pp. 251-282, aquí p. 273 (...aquilae Hesperiique simul pia signa leonis) y pp. 276, 281.

180 Cfr. Martin FRÜH, Profecía... [ver n. 17], p. 58 con n. 76. Véase en general sobre la comparación del rey Fernando con Hércules, Teresa JiMÉnEZ CALVENTE, Fernando... [ver n. 17], pp. 138-139 y 148-149. Sobre la evocación de la Edad de Oro véase ibid., p. 142 con n. 22.

181 Álvaro FERnández de CóRdOVA MiRALles, La emergencia... [ver n. 17], p. 58. Véase el sugerente análisis de la Oratio en Teresa JimÉNEZ CALVENTE, Fernando... [ver n. 17], p. 141, y también Edoardo D'ANGELO, L'Apostrophe... [ver n. 179], pp. 264-266.

182 Sobre este aspecto, véase Teresa JimÉNEZ CALVENTE, Fernando... [ver n. 17], p. 144.

183 Álvaro FERNÁNDEZ de CóRdova MiRALles, La emergencia... [ver n. 17], p. 56. 
tuales, que aparentemente no fueron impresos, y poco más tarde por un poema secular que sólo tenemos en forma manuscrita: la Apostrophe ad exleges Mauros, compuesta con la ocasión de la toma de Málaga en 1487, como nos enseña el filólogo italiano Edoardo d'Angelo ${ }^{184}$. En esta corriente propagandística clásicoalegorizante, Antonio Geraldini tuvo como sucesores, entre otros, a Pere Boscà, funcionario aragonés al servicio del cardenal Marco Barbo ${ }^{185}$, así como a su amigo florentino Ugolino Verino, quien va a escribir (instigado por nuestro poeta) su Panegyricon ad Ferdinandum regem et Isabellam reginam Hispaniarum de Saracenae Baetidos expugnatione ${ }^{186}$, y al poeta alcañizano Juan Sobrarias ${ }^{187}$.

No podemos cuantificar, en nuestros días, el éxito propagandístico de la obra religiosa de Antonio Geraldini. Nos queda, no obstante, el legado literario y espiritual de uno de los más interesantes protagonistas del humanismo peninsular del siglo $\mathrm{XV}$.

${ }^{184}$ Edoardo D’ANGELO, L'Apostrophe... [ver n. 179], pp. 260-261. Sobre las «sintonías ceremoniales» de esa campaña, véase Álvaro FERNÁNDEZ DE CóRDOVA MIRALLES, La emergencia... [ver n. 17], p. 67, y Edoardo D'ANGELO, L'Apostrophe... [ver n. 179], pp. 263-264; Nicasio SALVADOR MIGUEL, Pere Boscà y su Oratio romana (octubre de 1487) por la conquista de Málaga, en Aurora EGIDO y José Enrique LaPlaNA (eds.), La imagen... [ver n. 17], pp. 171-200, aquí pp. 171-174.

185 Álvaro FERNÁNDEZ de CóRdOVA MiRALles, La emergencia... [ver n. 17], pp. 59-60; Teresa JiMÉNEZ Calvente, Fernando... [ver n. 17], pp. 154-155; Nicasio SALvador Miguel, Pere Boscà... [ver n. 184].

186 Martin FrÜH, Antonio Geraldini... [ver n. 5], p. 158; Álvaro Fernández DE CóRdova MiRALLES, La emergencia... [ver n. 17], pp. 64-65; Teresa JimÉNEZ CALVENTE, Fernando... [ver n. 17], pp. 163-165.

187 Véase el análisis detallado en Teresa JimÉNEZ CALVENTE, Fernando... [ver n. 17], pp. 147-151. 
